\title{
Reduced Cortical Activity Impairs Development and Plasticity after Neonatal Hypoxia Ischemia
}

\author{
Sumudu Ranasinghe, ${ }^{1 \star}$ Grace Or, ${ }^{1 \star}$ Eric Y. Wang, ${ }^{1}$ Aiva Ievins, ${ }^{1}$ Merritt A. McLean, ${ }^{1}$ Cristopher M. Niell, ${ }^{3}$ Vann Chau, ${ }^{4}$ \\ Peter K. H. Wong, ${ }^{4}$ Hannah C. Glass, ${ }^{1,2}$ Joseph Sullivan, ${ }^{2}$ and Patrick S. McQuillen ${ }^{1,2}$ \\ Departments of ${ }^{1}$ Pediatrics and ${ }^{2}$ Neurology and ${ }^{3}$ W. M. Keck Foundation Center for Integrative Neuroscience, Department of Physiology, University of \\ California San Francisco, San Francisco, California 94143, and ${ }^{4}$ Department of Pediatrics, University of British Columbia, British Columbia Children's \\ Hospital, Vancouver, British Columbia, Canada V6H 3V4
}

Survivors of preterm birth are at high risk of pervasive cognitive and learning impairments, suggesting disrupted early brain development. The limits of viability for preterm birth encompass the third trimester of pregnancy, a "precritical period" of activity-dependent development characterized by the onset of spontaneous and evoked patterned electrical activity that drives neuronal maturation and formation of cortical circuits. Reduced background activity on electroencephalogram (EEG) is a sensitive marker of brain injury in human preterm infants that predicts poor neurodevelopmental outcome. We studied a rodent model of very early hypoxic-ischemic brain injury to investigate effects of injury on both general background and specific patterns of cortical activity measured with EEG. EEG background activity is depressed transiently after moderate hypoxia-ischemia with associated loss of spindle bursts. Depressed activity, in turn, is associated with delayed expression of glutamate receptor subunits and transporters. Cortical pyramidal neurons show reduced dendrite development and spine formation. Complementing previous observations in this model of impaired visual cortical plasticity, we find reduced somatosensory whisker barrel plasticity. Finally, EEG recordings from human premature newborns with brain injury demonstrate similar depressed background activity and loss of bursts in the spindle frequency band. Together, these findings suggest that abnormal development after early brain injury may result in part from disruption of specific forms of brain activity necessary for activity-dependent circuit development.

Key words: activity; hypoxia; ischemia; neonatal; plasticity; subplate

Significance Statement

Preterm birth and term birth asphyxia result in brain injury from inadequate oxygen delivery and constitute a major and growing worldwide health problem. Poor outcomes are noted in a majority of very premature ( $<25$ weeks gestation) newborns, resulting in death or life-long morbidity with motor, sensory, learning, behavioral, and language disabilities that limit academic achievement and well-being. Limited progress has been made to develop therapies that improve neurologic outcomes. The overall objective of this study is to understand the effect of early brain injury on activity-dependent brain development and cortical plasticity to develop new treatments that will optimize repair and recovery after brain injury.

\section{Introduction}

Survival after extreme preterm birth has improved significantly over the past two decades with the development of effective ther-

\footnotetext{
Received July 1, 2014; revised July 14, 2015; accepted July 14, 2015.

Author contributions: P.S.M. designed research; S.R., G.O., E.Y.W., A.I., M.A.M., V.C., P.K.H.W., H.C.G., J.S., and P.S.M. performed research;C.M.N. contributed unpublished reagents/analytic tools; S.R., G.O., A.I., M.A.M., J.S., and P.S.M. analyzed data; S.R., G.O., and P.S.M. wrote the paper.

This work was supported by National Institutes of Health Grants 5R01NS060896, 2R01NS46432, and K23NS066137 and Canadian Institutes for Health Research Operating Grant MOP-79262. We thank Dawn Gano for reviewing the manuscript and Jim Barkovich, Duan Xu, and University of California San Francisco Clinical and Translational Science Institute Research Nurses for providing clinical data.

The authors declare no competing financial interests.

*S.R. and G.O. contributed equally to this work.

Correspondence should be addressed to Patrick S. McQuillen, 521 Parnassus Avenue, University of California San Francisco Medical Center, San Francisco, CA 94143-0106. E-mail: patrick.mcquillen@ucsf.edu.
}

apies to support immature lungs (Costeloe et al., 2012). However, the incidence of adverse neurodevelopmental outcome is inversely correlated with gestational age (GA) at birth (Moore et al., 2012). Thus, increasing survival after extremely preterm birth comes with a burden of more children suffering cognitive impairments (Wilson-Costello et al., 2005). The neurobiological substrates of impaired brain function after extreme preterm birth are not completely understood.

Despite clinical data demonstrating that altered patterns of early brain electrical activity recorded by electroencephalogram (EEG) are highly predictive of subsequent neurodevelopmental 
outcome (Toet et al., 1999; Wikström et al., 2012), few preclinical studies have considered the effects of early brain injury on neuronal activity. Furthermore, the developmental mechanisms, structure, and functions of early patterned brain activity have not been fully appreciated by clinicians, in part because of standard EEG recording conditions that filter slow frequencies (Vanhatalo and Kaila, 2006). Accumulating evidence suggests that the developing CNS relies on spontaneous and evoked rhythmic activity for functional development of neuronal circuits before the onset of well studied critical periods of plasticity (Feller and Scanziani, 2005; Hanganu-Opatz, 2010). EEG during this "precritical" period is characteristically discontinuous with periods of silence, followed by bursts of stereotypical oscillatory activity, including slow activity transients (SATs), delta waves, and spindle bursts or delta brushes. Spontaneous oscillations are observed throughout the developing CNS with common features that provide strong, correlated activity to immature, poorly responsive circuits (Blankenship and Feller, 2010). Electrical activity drives gene expression (West and Greenberg, 2011) and morphological neuronal development (Spitzer, 2006). Spontaneous activity propagates through multiple levels (Ackman et al., 2012) and is instructive for circuit development (Cang et al., 2005; Xu et al., 2011), culminating in the maturation of visual responses (Colonnese et al., 2010 ) and refinement of sensorimotor connections (Khazipov et al., 2004).

To determine the effects of brain injury on early brain activity and subsequent cortical development and plasticity, we analyzed EEG recordings from a well characterized rodent model of cerebral hypoxia-ischemia (HI) and in a cohort of human preterm newborns with and without brain injuries identified with magnetic resonance imaging (MRI). We find that early brain injury transiently suppresses background activity by increasing interburst interval (IBI) and decreases specific forms of patterned activity, including bursts in the spindle frequency band $(8-30 \mathrm{~Hz})$. In rodents, these transient changes in activity are associated with multiple changes in activity-regulated protein expression, neuronal morphology, and cortical plasticity.

\section{Materials and Methods}

All animal research was approved by the University of California San Francisco (UCSF) Committee on Animal Research and performed in accordance with standards for humane animal treatment as outlined in the Policy on Humane Care and Use of Laboratory Animals. Long-Evans dams (Simonsen) with litters were allowed food and water ad libitum.

HI. HI was performed as described previously (McQuillen et al., 2003; Failor et al., 2010). Postnatal day 2 (P2) ( $\pm 0.5 \mathrm{~d}$ based on overnight breeding) pups of either sex were individually anesthetized with isoflurane, and the right common carotid artery was dissected free and electrocauterized. Pups were recovered with the mother for $1 \mathrm{~h}$ and then placed in temperature-controlled chambers to maintain a chamber temperature of $34^{\circ} \mathrm{C}$ and a rat skin surface temperature of $36.5-37^{\circ} \mathrm{C}$. Hypoxia was achieved with $5.6 \%$ oxygen gas as described previously (Towfighi et al., 1997). Duration of hypoxia ranged between 2.5 and 3 h, with the hypoxia period terminated if any animal appeared premorbid or the mortality for any individual litter reached $20 \%$.

Determination of cortical injury severity. After HI, injury severity was defined categorically based on histology or MRI as described previously (Failor et al., 2010) and confirmed with stereologic infarct volume measured on coronal sections stained with cresyl violet or nuclear counterstain (To-Pro-3; Life Technologies). Hemispheric volume was measured using Cavalieri's principal and StereoInvestigator software (MBF Bioscience). Injury categories displayed the following infarct volumes: (1) mild, $0-7 \%$; (2) moderate, $8-19 \%$; and (3) severe, $>20 \%$. Tissue was prepared for Western blotting using MRI $24 \mathrm{~h}$ after $\mathrm{HI}$ to select cases with moderate injury as described previously (Failor et al., 2010).
EEG head-mount surgery. Twenty-four hours after HI, pups were anesthetized with isoflurane, the scalp was sterilized with topical povidoneiodine, and a midline incision was made to expose the skull. Holes were drilled at the following locations bilaterally: $1.5 \mathrm{~mm}$ posterior of bregma and $1.0 \mathrm{~mm}$ anterior of lambda at $2.5 \mathrm{~mm}$ lateral of the midsagittal suture. The ground electrode was placed over the midcerebellum. Silver ball electrodes were made from 0.003 -inch gauge silver wire (A-M Systems) as described previously (Nakano et al., 1994). Electrodes were placed through the burr holes to settle between the dura and the skull and sealed with a small amount of cyanoacrylate. They were then soldered to the EEG head mount (Pinnacle Technology), which was secured in the middle of the skull with cyanoacrylate. All the exposed wires were covered with dental acrylic. The pups are allowed to recover and returned to the dam.

EEG recording. EEG was recorded using a PAL-8200 data acquisition system (Pinnacle Technology) through a head-mounted preamplifier with integrated $0.5 \mathrm{~Hz}$ high-pass filter. Freely moving animals were connected by a tether to the data acquisition card and amplifier and kept in a temperature-controlled recording chamber lined with bedding. Independent signals were recorded from the two hemispheres with a ground over the cerebellum, thus allowing them to be analyzed individually. The EEG signal was filtered $(0.5-40 \mathrm{~Hz})$, amplified, and recorded at a sampling rate of $400 \mathrm{~Hz}$. EEG was recorded from each animal continuously for 1-2 h every alternative day up to P17. A limited number of recording channels precluded recording electromyogram signal to precisely define state. During this age range, immature rats cycle between brief periods of wakefulness $(<20 \%$ of time), characterized by high nuchal tone and coordinated movements, and quiet or active sleep (Seelke and Blumberg, 2008). Wakeful periods accompanied by noticeable movement artifact on the EEG trace precluded analyses and were avoided. Animals with moderate injury were selected by histological criteria as described previously (Failor et al., 2010) and with measurement of stereologic infarct volume after perfusion after P17.

EEG data analysis. Raw EEG recordings were imported into MATLAB (MathWorks) for processing. To derive the amplitude integrated EEG (aEEG), recordings were bandpass filtered $(2-15 \mathrm{~Hz})$, rectified, smoothed, and plotted with time compression $(\sim 5 \mathrm{~cm} / \mathrm{h})$ to replicate the approach described for monitoring human newborns (Maynard et al., 1969; Toet et al., 1999; Wikström et al., 2012). The aEEG lower and upper margin amplitudes were identified by plotting a smoothed curve of the 10 th and 90th percentiles of aEEG values, respectively, over time. A 10 min segment of movement artifact-free recording were selected from inspection of the aEEG for analyses. The presence or absence of cyclicity was noted (Kidokoro et al., 2012). When cyclicity was present, the segment chosen avoided periods of lowest aEEG margin. The median value of 10 th (Fig. 1B, blue line) and 90th (Fig. $1 B$, red line) percentiles for the selected time period is recorded as the estimate of lower and upper margin amplitude, respectively. To identify EEG activity bursts and IBIs, we plotted the EEG root mean squared (RMS) amplitude over a 1-sduration sliding window. A burst was defined as an increase in the RMS amplitude above threshold for $>100 \mathrm{~ms}$ and $<20$ s beyond which EEG activity was defined as continuous (Hayakawa et al., 2001; Tucker et al., 2009). The minimal IBI was defined as $1 \mathrm{~s}$ (Hayakawa et al., 2001). IBIs were recorded, along with burst duration and number. For animal EEG, RMS threshold for burst onset was derived empirically at each age in control animals to account for the developmental increase in peak-topeak EEG amplitude. Thresholds increased from $2.5 \mu \mathrm{V}$ at $\mathrm{P} 4$ to $12 \mu \mathrm{V}$ at P14, which were used subsequently to analyze EEG from hypoxia and HI hemispheres. For the human data, each recording was processed using an automated approach that evaluates a continuous range for burst thresholds. The burst threshold was chosen individually at the $80 \%$ percentile of the threshold that detects the maximal number of bursts for each subject. Bursts in the spindle frequency were identified using a similar algorithm applied to bandpass-filtered $(8-30 \mathrm{~Hz})$ EEG recordings.

Western blotting. Cortical tissue was dissected from Long-Evans rats at P3 and P7 in controls or after HI with moderate injury at P2. HI animals were selected by MRI at P3 for moderate injury as described previously (Failor et al., 2010). Synaptosome fractions were purified from tissue (Goebel-Goody et al., 2009), and immunoblots were performed as de- 
scribed previously (Failor et al., 2010) using the following antibodies: anti-NR1 (1:1000; Millipore), anti-NR2A (1:1000; Millipore), antiNR2B (1:1000; Millipore), AMPA glutamate receptor 1 (GluR1; 1:1000; Millipore), GluR2 (1:1000; Millipore), postsynaptic density 95 (PSD95; 1:1000; Thermo Fisher Scientific), glutamate-aspartate transporter (GLAST; 1:1000; Millipore), and Actin (1:20,000; Sigma-Aldrich). After being washed three times for $10 \mathrm{~min}$ in $0.01 \mathrm{M}$ PBS with $0.1 \%$ Tween 20, membranes were incubated for $2 \mathrm{~h}$ at room temperature with fluorophoreconjugated secondary antibodies in blocking buffer, including IRDye 680RD donkey antimouse IgG (heavy and light chain; 1:15,000; Li-Cor) for glutamate NMDA receptor 1 (NR1), NR2B, GluR2, PSD95, and Actin and IRDye 800CW goat anti-rabbit IgG (heavy and light chain; 1:15,000; Li-Cor) for NR2A, GluR1, and GLAST. At the end of the secondary antibody incubation, the blots were washed three times for $10 \mathrm{~min}$ in $0.01 \mathrm{M}$ PBS. They were then scanned in the Odyssey Infrared Fluorescent Scanner (Li-Cor). Band optical densities were measured using Odyssey Software (Li-Cor). For each sample, we calculated the normalized ratio of protein/Actin values, and these numbers were used to calculate the mean and SD.

Immunohistochemistry. Coronal sections (50 $\mu \mathrm{m})$ were dry mounted and incubated overnight at $4^{\circ} \mathrm{C}$ in blocking solution $(5 \%$ donkey serum, $5 \%$ fish skin gelatin, $0.1 \%$ Triton $\mathrm{X}-100$, and $0.1 \% \mathrm{w} / \mathrm{v} \mathrm{BSA}$ ) with a combination of the following primary antibodies: rabbit anti-GluR1 (1:300; Millipore) or rabbit antiSynapsin 1 (1:900; Abcam) and mouse antiFoxP1 (1:900; Abcam). After three 5-min washes in $0.05 \%$ Tween 20 in PBS, sections were incubated for $2 \mathrm{~h}$ at room temperature in blocking solution with the following secondary antibodies: anti-rabbit Alexa Fluor 647 (1:300; Jackson ImmunoResearch) and anti-mouse Alexa Fluor 488 (1:300; Jackson ImmunoResearch). Sections were washed three times for 5 min each and coverslipped with ProLong Gold.

Puncta density quantification. Tissue sections stained for a layers III-V marker (Foxp1) and synaptic protein (GluR1 or Synapsin 1) were imaged using a Zeiss AxioImager with ApoTome and $63 \times$ objective. $z$-Stack images were taken at five sampling sites from each of the upper, middle, and lower zones targeting layers II, IV, and VI of the primary somatosensory (S1) cortex. The thickness of the z-stack was $3.15 \mu \mathrm{m}$, and the interval between slices was $0.35 \mu \mathrm{m}$. Using the spot-detection feature in the Imaris software (Bitplane), the number of synaptic protein puncta was quantified for each $\mathrm{z}$-stack image. The quantification was conducted blind to injury condition (control, hypoxia, or $\mathrm{HI}$ ).

Viral green fluorescent protein labeling. Adeno-associated virus (AAV) vectors containing the cassettes for AAV2/9.CMV.PI.Cre.RBG and AAV2/9 CAG.FLEX.EGFP.WPRE.bGH (Allen Institute 854) were obtained from the University of Pennsylvania Viral Vector Core. To obtain sparse labeling, AAV2/9.CMV.PI.Cre.RBG was diluted 1:10,000 (initial titer, $4.92 \times$ $\left.10^{13}\right)$ and combined with full-titer $\left(1.53 \times 10^{13}\right)$ AAV2/9.CAG.FLEX.

B

C
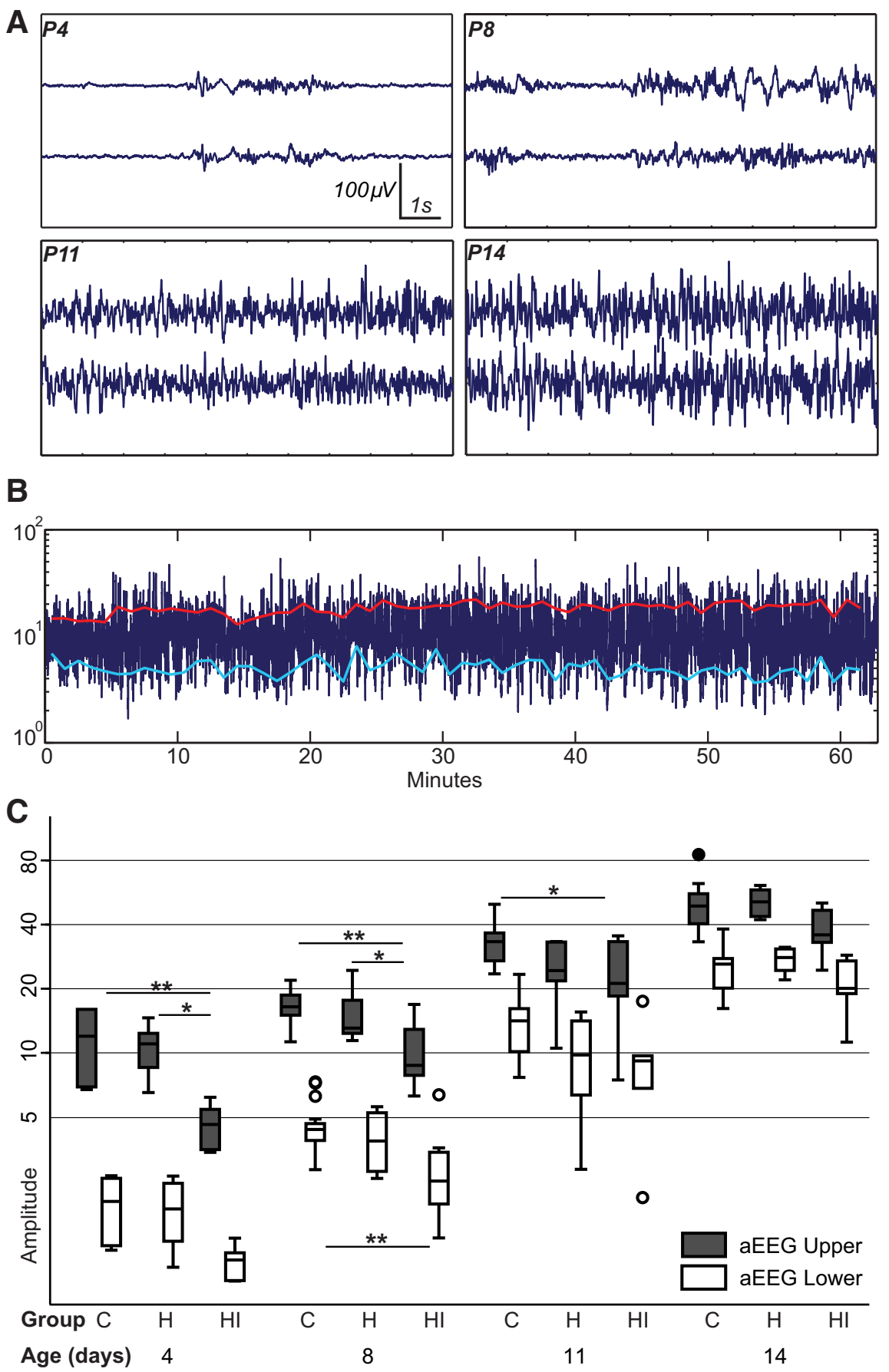

Figure 1. Neonatal rat $\mathrm{EEG} . A$, Representative biparietal raw EEG traces from control rats at ages P4 - P14 showing increase in peak-to-peak amplitude and the gradual development of continuous activity with development. $B, A 60$ min aEEG trace produced by bandpass filtering $(2-15 \mathrm{~Hz}$ ), rectifying, and time compressing the raw EEG. The median value of 10th (blue line) and 90 th (red line) percentiles is recorded as the estimate of lower and upper margin amplitude, respectively. C, Summary of aEEG lower (white) and upper (black) margin amplitudes with increasing maturity under normal development $(\mathrm{C}$, control) and after $\mathrm{HI}$ at $\mathrm{P} 2(\mathrm{H}$, hypoxia; HI, hypoxia-ischemia). Statistical significance determined for overall difference with linear regression for repeated measures, generalized estimating equation accounting for repeated measures by animal. Individual differences at each age determined by Kruskal-Wallis test with Bonferroni's correction. ${ }^{*} p<0.05,{ }^{* *} p<0.01$. $n$ values: control, $\mathrm{P} 4 n=6, \mathrm{P} 8 n=17$, $\mathrm{P} 11 n=12, \mathrm{P} 14 n=13 ; \mathrm{H}$ and HI, P4 $n=6, \mathrm{P} 8 n=9, \mathrm{P} 11 n=7, \mathrm{P} 14 n=5$.

EGFP.WPRE.bGH and fast green dye. Stereotaxic injections were performed in P1 Long-Evans rats immobilized using a neonatal stereotaxic frame (Stoelting). Pups were anesthetized with hypothermia. Forty-five nanoliters of the virus and dye mixture were injected through a pulled glass pipette, with tip diameter of $50 \mu \mathrm{m}$, three injection sites per hemisphere. 
Dendrite morphological analysis. Virus-injected control and HIexposed rats were killed with pentobarbital and perfused with an ice-cold solution of $4 \%$ paraformaldehyde (PFA). Brains were postfixed in $4 \%$ PFA for $24 \mathrm{~h}$ and vibratome sectioned at $300 \mu \mathrm{m}$ thickness. Animals with moderate injury were selected by histological criteria as described previously (Failor et al., 2010) and with measurement of stereologic infarct volume. AAV-labeled green fluorescent protein (GFP) neurons were amplified through immunofluorescence. z-Stacks of layer V excitatory neurons were acquired on a Zeiss AxioImager with ApoTome (Carl Zeiss) using a $20 \times$ objective. Dendrites were reconstructed in $3 \mathrm{D}$ automatically and edited manually using the FilamentTracer module in the Imaris software (Bitplane) for analysis of dendritic length, Sholl analysis, and branch number. Segments of dendrites from layer $V$ excitatory neurons were imaged for spines using the Zeiss AxioImager with ApoTome on a $63 \times$ objective. After acquiring a $z$-stack, the maximum image projection was used to reconstruct and quantify spine density.

Somatosensory whisker barrel plasticity. To induce whisker barrel plasticity, control and HI-exposed rats received bilateral C-row whisker follicle lesion while anesthetized for carotid ligation during (P1-P3) and after (P5, P7) the critical period for lesion-dependent whisker barrel plasticity (Jeanmonod et al., 1981). A small incision was made between C and D rows, and C1-C4 whisker follicles were removed with fine forceps. After recovery, rat pups underwent temperature-controlled hypoxia for an age-adjusted time period: (1) 5.6\% oxygen: $3-3.5 \mathrm{~h}$ for P1, 2.5-3 h for P2, and 2-2.5 h for P3; and (2) 8\% oxygen: $2 \mathrm{~h}$ for P5 and $1 \mathrm{~h}$ for P7. Animals were killed at P12 and perfused transcardially with cold saline, followed by $4 \%$ PFA. Cortical hemispheres were dissected free from the midbrain, and relieving cuts were made at the margins of the hemispheres before flattening between two glass slides separated by plastic spacers. Flattened hemispheres were postfixed and cryoprotected in a sucrose/PFA solution. Tangential sections were cut on a freezing microtome and reacted with an optimized cytochrome oxidase staining protocol as described previously (Conway et al., 2000). Only sections containing complete barrel fields were imaged and analyzed. A minority of animals had gross disruption of the barrel fields or cyst formation indicative of severe injury. Digital images were acquired and analyzed in Fiji using the autothreshold function to measure C- and D-row areas (Schindelin et al., 2012).

Human EEG recordings. Preterm newborns ( $<33$ weeks of GA at birth) admitted to the intensive care nurseries at the UCSF Benioff and University of British Columbia (UBC) Children's Hospitals who consented for an ongoing prospective, observational neuroimaging study were included if they also have received an early EEG recording. At UBC, EEG was performed for clinical indications (e.g., encephalopathy or clinical seizure). At UCSF, EEG was collected prospectively as part of the research protocol. Neuroimaging results from this study have been reported previously (Miller et al., 2005; Glass et al., 2009). Exclusion criteria include the following: (1) congenital malformation or syndrome; (2) congenital infection; and (3) newborns too clinically unstable for transport to the MRI scanner. Parental consent was obtained for all cases following a protocol approved by both institutional committees on human research. At UCSF, EEG was recorded using a NicoletOne (Natus Medical) EEG monitoring system with electrodes placed according to the international 10-20 system, modified for neonates. At UBC, EEG was recorded using the Biologic CeeGraph (Natus Medical) system. In control subjects and cases with bilateral brain injury on MRI, measurements were taken from each hemisphere and averaged. For subjects with asymmetric injury [e.g., grade III intraventricular hemorrhage (IVH) and periventricular hemorrhagic infarction], measurements were taken from the injured hemisphere.

Statistics. Statistical analysis was performed in Stata version 13 (StataCorp). Data were initially examined graphically using scatter plots, Kaplan-Meier curves, and box plots of median, interquartile range, and outliers. For difference testing among conditions in which individual measurements were made, one-way ANOVA with Bonferroni's correction (e.g., Western blot, somatosensory barrel plasticity) or Student's $t$ test (e.g., human EEG recordings) were used. Difference testing in experiments with repeated measurements (e.g., rat EEG recordings, dendrite complexity, spine density) was tested initially using linear regression for repeated measures, generalized estimating equation accounting for the number of animals studied. Only if a significant overall difference was identified using ANOVA, Kruskal-Wallis, or linear regression for repeated measures were pairwise comparisons determined with Bonferroni's correction or Tukey's post hoc test for rat aEEG margins, IBI, rat spindle burst count, dendrite number, Sholl analysis by radius, spine density, and puncta density. Clinical variables for human preterm newborns were compared with Kruskal-Wallis or Fisher's exact tests. The associations of clinical variables (e.g., GA, brain injury, and medication exposure) with human spindle-like bursts were tested initially with univariate linear regression. Variables with $p<0.1$ (brain injury and phenobarbital treatment) or known association (GA) were combined into a multivariable linear model. The nonparametric test for trends across ordered groups was used to determine effects of injury type and severity.

\section{Results}

Diminished background activity after $\mathrm{HI}$ in neonatal rodents Given the critical role of patterned neuronal activity for normal cortical development in the precritical period (Feller and Scanziani, 2005), as well as the participation of subplate neurons in transient circuits that function to transmit activity to developing cortex (DuPont et al., 2006; Tolner et al., 2012) and their loss in following HI (McQuillen et al., 2003), we sought to characterize cortical activity by recording bilateral parietal EEG in rat pups after P2 HI or in controls. In the very immature brain (P4-P8), EEG activity in both groups was discontinuous with bursts of low-amplitude activity, followed by quiescent intervals (Fig. $1 \mathrm{~A}$, P4, P8). The peak-to-peak amplitude gradually increased and EEG activity became continuous around eye opening at P14 (Fig. $1 A, \mathrm{P} 11, \mathrm{P} 14)$. aEEG is a trending tool used commonly in clinical neonatal intensive care units to identify brain-injured newborns (Toet et al., 1999; Wikström et al., 2012). To produce aEEG traces, raw EEG recordings were bandpass filtered $(2-15 \mathrm{~Hz})$, rectified, and time compressed as described previously (Maynard et al., 1969; Fig. 1B). In control animals, aEEG upper and lower margin amplitudes increase with development (Fig. 1C, Group C), consistent with published results using a clinical aEEG device (Tucker et al., 2009). In moderately injured animals, aEEG upper and lower margins are significantly lower in the ipsilateral HI hemisphere compared with the control or hypoxia hemispheres (upper margin, $p<0.001$; lower margin, $p=0.001$ ). Upper margins are lower than the control or hypoxia condition from $\mathrm{P} 4$ to P8 and lower than control at P11 (Fig. 1C). aEEG lower margins are decreased in HI hemispheres compared with control at P4 and P8. By P14, background activity has normalized in moderately injured animals. (Fig. 1C).

\section{Prolonged IBIs and reduced spindle bursts}

To determine whether lower aEEG margins in injured animals resulted from increasing discontinuity of background activity, EEG recordings were analyzed to measure IBIs and to identify bursts of activity in the spindle frequency band $(8-30 \mathrm{~Hz})$ using an automated analysis (Fig. 2A). To identify bursts and IBIs, we developed an approach similar to that reported for quantification of high-frequency bursts in humans (Myers et al., 2012). An IBI is initiated when the EEG RMS power decreases below an agedependent threshold for $>1 \mathrm{~s}$ (Fig. $2 A$ ). In contrast, a burst was defined as an increase in RMS power over threshold for $>100 \mathrm{~ms}$ but $<20 \mathrm{~s}$, a time period beyond which EEG activity was deemed continuous. The number and length of bursts and IBIs were determined. Analysis of IBIs across injury conditions [control (C), hypoxia $(\mathrm{H})$ only, and (HI)] shows that the population of IBIs in the $\mathrm{HI}$ injured brain is significantly prolonged compared with the control and hypoxic brains at P4 and P8 (Fig. 2B, P4 and P8, both 

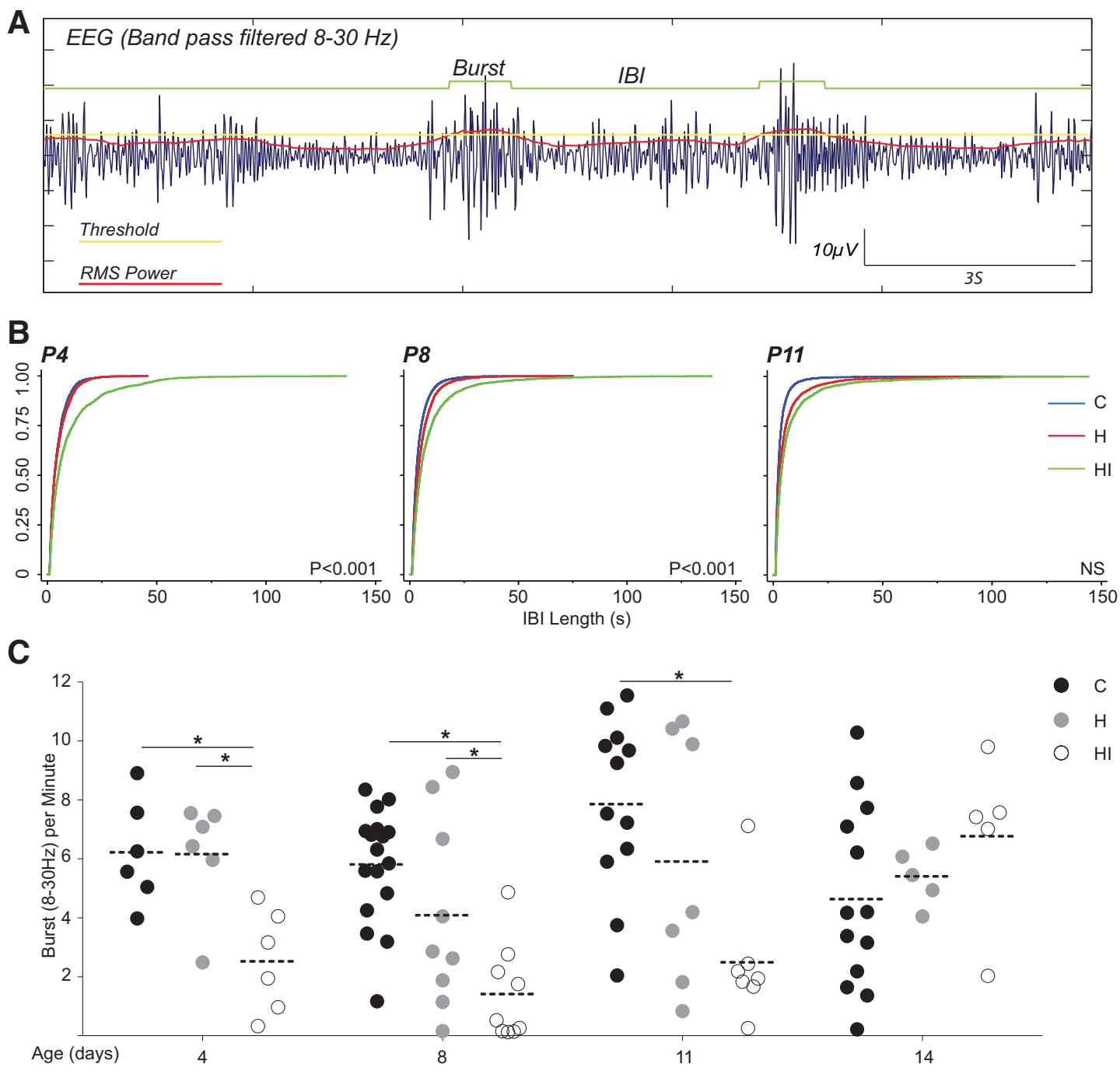

Figure 2. IBI and spindle burst detection after $\mathrm{HI}$ at $\mathrm{P} 2$ in neonatal rat. $\boldsymbol{A}$, Representative $\mathrm{EEG}$ trace from a control P8 rat illustrating IBl and burst detection on a bandpass-filtered (8 -30 $\mathrm{Hz}$ ) $\mathrm{EEG}$ trace. Red line represents the RMS amplitude, the yellow line represents the empirical threshold for P8, and the green line indicates the bursts and IBIs. B, Population distribution graphs of IBIs of neonatal rats at P4, P8, and P11 in control (C) animals (blue) and after HI at P2 (H, red; HI, green). C, Number of spindle bursts per minute in each animal for control (black), $\mathrm{H}$ (gray), and HI (white) hemispheres (dashed line is population mean) for each group from P4 to P14. Statistical significance determined with linear regression for repeated measures, generalized estimating equation accounting for repeated measures by animal. ${ }^{*} p<0.05$. $n$ values: control, P4 $n=6, \mathrm{P} 8 n=17, \mathrm{P} 11 n=12, \mathrm{P} 14 n=13 ; \mathrm{H}$ and HI, P4 $n=6, \mathrm{P} 8 n=9, \mathrm{P} 11 n=7, \mathrm{P} 14 n=5$.

$p<0.001)$. By P11, IBIs are prolonged in both hypoxia and HI hemispheres compared with control, although this difference is not significant (Fig. 2B, P11). After P11, EEG activity became continuous in all groups.

Activity bursts in immature occipital and parietal cortex are characterized by oscillations with nested waves at specific frequency bands from ultra-slow $(0.01-0.2 \mathrm{~Hz})$ to alpha-beta $(8-30 \mathrm{~Hz})$ and gamma $(30-50 \mathrm{~Hz}$; Hanganu-Opatz, 2010). In developing rodent cortex, a characteristic activity pattern is the cortical spindle burst, defined as "spindle-shaped" field oscillations at frequencies between 8 and $30 \mathrm{~Hz}$ (Khazipov et al., 2004). Cortical spindle bursts may occur as isolated events or may be coincident with high-amplitude, slow-frequency events termed SATs (Colonnese and Khazipov, 2010). Cortical spindle bursts are lost after specific removal of subplate neurons (Tolner et al., 2012), and subplate neurons are known to be among vulnerable cell populations after early HI (McQuillen et al., 2003). To determine whether P2 HI disrupts spindle bursts, we repeated the burst/IBI analysis on EEG recordings that were bandpass filtered in the spindle frequency range $(8-30 \mathrm{~Hz})$. The number of cortical spindles per minute was reduced significantly in the HI hemisphere compared with the hypoxia-only and control hemispheres (Fig. 2C) at P4 and P8. At P11, spindle burst frequency remained lower than the HI hemisphere compared with control. Spindle burst frequency trended higher in the HI hemisphere at P14 (Fig. $1 A, \mathrm{P} 14)$. Spindle burst duration remained unchanged after $\mathrm{HI}$ (mean burst length: P4, $1.5 \mathrm{~s}(\mathrm{C}), 1.4 \mathrm{~s}(\mathrm{H}), 1.3 \mathrm{~s}(\mathrm{HI}), p=0.83$; P8, $1.1 \mathrm{~s}(\mathrm{C}), 0.9 \mathrm{~s}(\mathrm{H}), 0.8 \mathrm{~s}(\mathrm{HI}), p=0.08$; P11, $1.5 \mathrm{~s}(\mathrm{C}), 1.1 \mathrm{~s}$ $(\mathrm{H}), 0.9 \mathrm{~s}(\mathrm{HI}), p=0.13)$.

\section{Delayed activity-dependent protein expression}

Glutamate receptor and PSD subunit expression are developmentally regulated (Sans et al., 2000) and regulated by neuronal activity (West and Greenberg, 2011). To determine whether reduced cortical activity after P2 HI was associated with reduced activity-dependent protein expression, we analyzed the synaptic fractions of control, hypoxia, and HI cortices by Western blot analysis at P3 and P7. At these young ages, glutamate receptor subunits are expressed at levels too low to be detected in whole lysates. In a previous study, we have shown that expression levels 

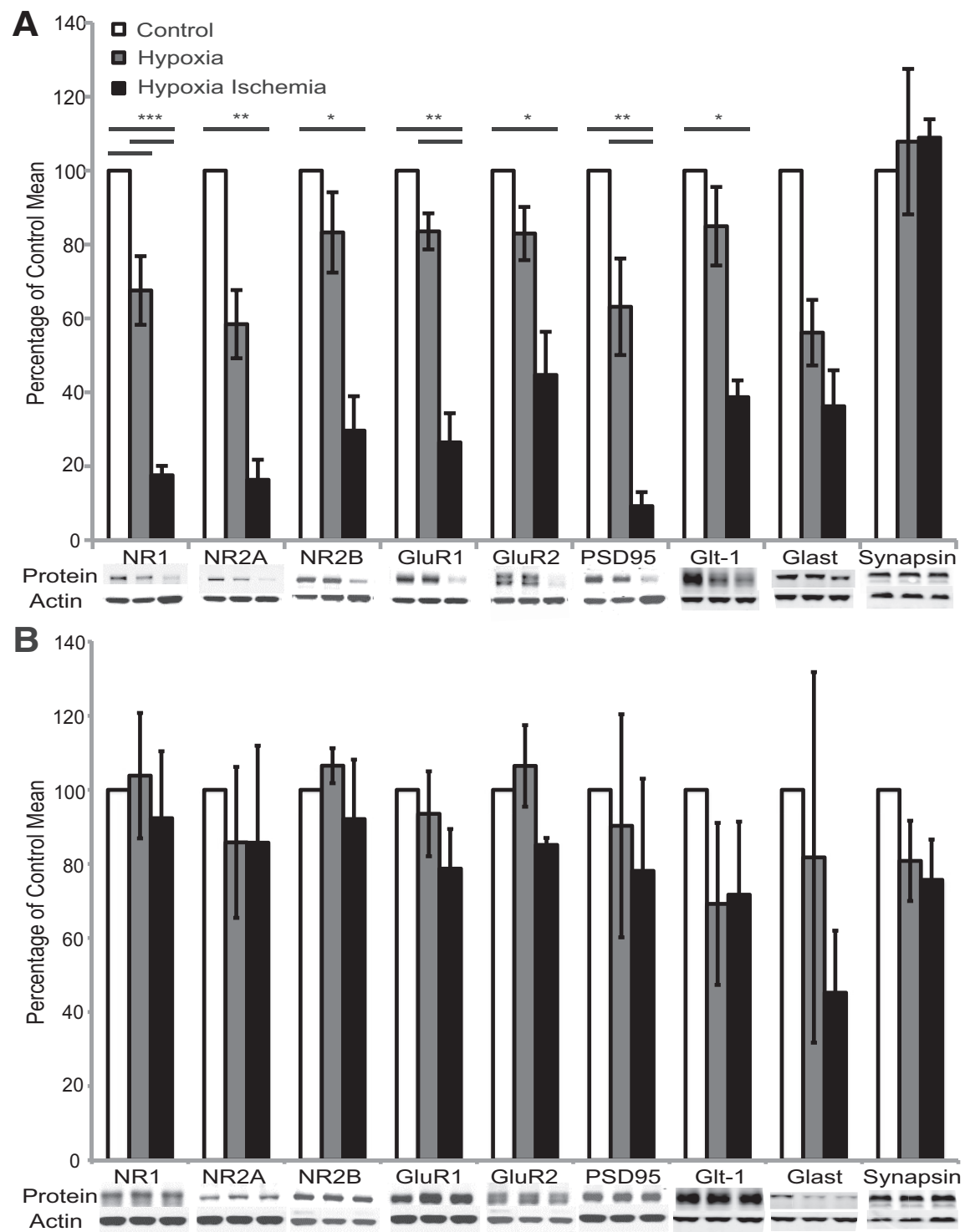

Figure 3. Activity-dependent protein expression. Quantification of protein expression in the synaptic fractions of control, hypoxia-only, and HI tissue was analyzed by immunoblot. At P3 (A), NR1, NR2A, NR2B, GluR1, GluR2, PSD95, and GLT1 expression is significantly reduced in the HI hemisphere when compared with control tissue. GLAST expression trends to reduced but did not reach significance. Synapsin expression is unchanged across conditions. NR1 expression is also reduced in the hypoxia-only hemisphere compared with control. At P7 (B), protein expression levels are not significantly different from normal expression levels. Results are plotted normalized to control level expression to include all data on a single plot. Significance testing was determined using one-way ANOVA with Bonferroni's correction and was performed on Actin normalized data. ${ }^{*} p<0.05,{ }^{* *} p<0.01,{ }^{* * *} p<$ 0.001 .

of these proteins are not different from control at P14 after P2 HI (Failor et al., 2010). At P3, expression of NR1, NR2A, NR2B, GluR1, GluR2, and PSD95 were decreased significantly in HItreated hemispheres (Fig. $3 A$, all $p<0.05$ ). In addition, glutamate transporter 1 (GLT1) and GLAST expression was lower, although this did not reach significance for GLAST. NR1 levels were significantly lower in the hypoxia hemisphere compared with control. In contrast, the presynaptic protein Synapsin 1 was unchanged in hypoxia and HI hemispheres compared with control (Fig. 3A). NR1 is localized primarily to the synaptic membrane fraction but can also be detected in extrasynaptic membrane fractions. After HI, we did not detect any changes in the relative localization or amounts of NR1, NR2A, or NR2B in extrasynaptic compared with synaptic fractions (all $p>0.2$; data not shown), which might be suggestive of a change in NMDA receptor localization or composition. By P7, expression levels for all proteins had increased in hypoxia and HI hemispheres and were no longer significantly different from control expression levels (Fig. 3B).

Given these findings, we investigated whether the depressed GluR1 expression is specific to certain cortical layers. We used the cortical layer marker FoxP1, a transcription factor expressed in layers III-V during postnatal ages (Hisaoka et al., 2010). By placing the sampling sites below the cell-sparse layer I, in the middle of the FoxP1-positive band and within FoxP1-negative lower cortex, we could target layers II, IV, and VI, respectively (Fig. 4A-C). After P2 HI, there is no significant reduction in GluR1 density in layer II of S1 cortex at P3 compared with control and hypoxia hemispheres (Fig. $4 D)$. However, GluR1 density is significantly decreased in layer IV (Fig. $4 D ; p<$ 0.01 vs $\mathrm{C}, p<0.01$ vs $\mathrm{H}$ ) and layer VI (Fig. $4 E ; P<0.001$ vs $C, p<0.001$ vs. $H)$ of the $S 1$ cortex after HI. In contrast and in accord with our Western blot analysis, there are no significant differences in Synapsin 1 density between control, hypoxia, and $\mathrm{HI}$ hemispheres in the upper, middle, and lower layers (Fig. 4E).

\section{Impaired neuronal dendrite and spine development}

Neuronal activity is required for normal development of dendrites (Chen and Ghosh, 2005) and spines (Saneyoshi et al., 2010). To correlate changes in activity after neonatal HI with changes in dendritic morphology, we labeled cortical neurons sparsely and brightly with GFP to facilitate complete reconstruction of individual neuronal dendritic arbors at P14 (Fig. 5A$C)$. Individual spiny neurons in layer $\mathrm{V}$ neurons were imaged, reconstructed, and analyzed for number, length, branching, and complexity (Fig. 5A-C). After P2 HI, cortical pyramidal neurons in the $\mathrm{HI}$ hemisphere have simpler dendritic trees at P14 manifested by decreased dendrite number (Fig. 5D; $p<0.001$ ) and lower total dendrite length (Fig. 5E; $p=0.03$ ) compared with control and hypoxia-only brains. Similarly, node number (Fig. 5F; $p<0.001$ ) is decreased in HI compared with control and hypoxia only. Finally, Sholl analysis (Fig. 5G) confirmed a simplified dendritic arborization in the $\mathrm{HI}$ hemispheres with a significantly decreased number of intersections $20-60 \mu \mathrm{m}$ away from the soma $(p<$ $0.001)$.

To further understand the changes in activity after neonatal HI, we imaged dendritic spines with high-resolution structured illumination microscopy. Segments of dendrite were reconstructed and spines were identified and counted in the layer $\mathrm{V}$ neurons. Primary and secondary dendrites from the HI-exposed hemisphere had a significantly decreased overall spine density 

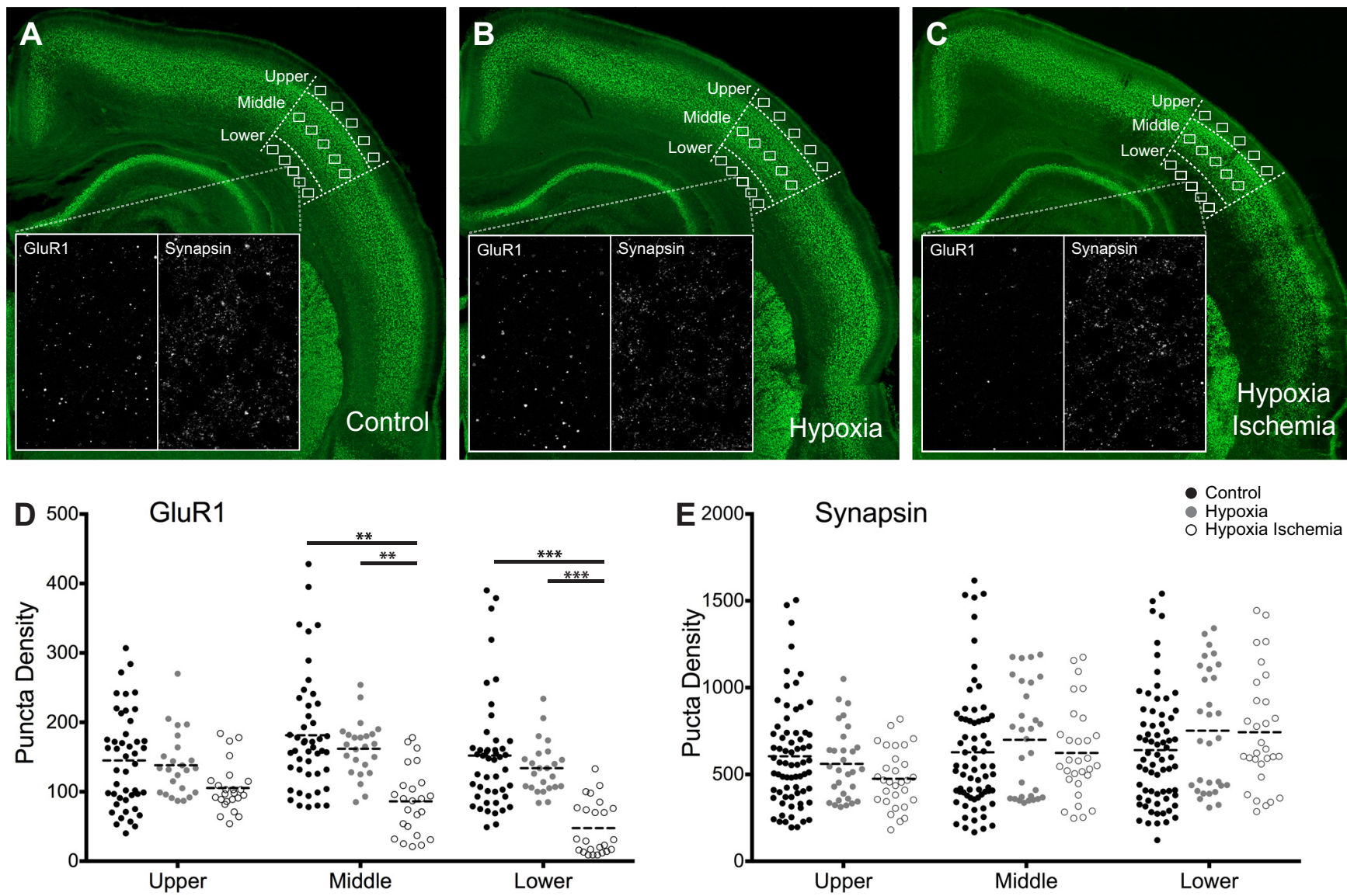

Figure 4. Layer-specific deficits in synaptic protein expression after HI. Immunohistochemical costainings of a synaptic protein, GluR1 or Synapsin, and a layer III-V marker, Foxp1, were performed on control $(\boldsymbol{A})$, hypoxia $(\boldsymbol{B})$, and $\mathrm{HI}(\boldsymbol{C})$ hemispheres at P3. The puncta densities of GluR1 and Synapsin were quantified for each of the upper, middle, and lower zones of the S1 cortex. There were no significant differences in GluR1 density between the control, hypoxia, and HI hemispheres in the upper layer, but the middle and lower layers of the HI hemisphere were significantly reduced (D). There were no significant differences in Synapsin density in any of the cortical layers between control, hypoxia, and $\mathrm{HI}$ hemispheres $(\boldsymbol{E})$. Statistical significance was determined with linear regression for repeated measures, generalized estimating equation accounting for repeated measures by animal. ${ }^{* *} p<0.01{ }^{* *} p<0.001 . n$ values: control, $\mathrm{n}=7 ; \mathrm{H}$ and $\mathrm{HI}, n=5$.

(mean \pm SD spine density: control, $0.47 \pm 0.22 ;$ hypoxia, $0.37 \pm$ $0.16 ; \mathrm{HI}, 0.30 \pm 0.09 ; p<0.001)$. Spine density was significantly lower in both primary and secondary dendrites (Fig. $6 D, E ; p<$ $0.05)$. Spine density trended lower in the hypoxia condition especially in primary dendrites, although this did not reach significance $(p=0.07)$.

\section{Decreased whisker barrel plasticity after early HI}

Early HI brain injury impairs subsequent ocular dominance plasticity during the critical period (P28-P32; Failor et al., 2010). In light of the acute reduction in background activity (Fig. 1) and transient decrease in the expression of glutamate receptor subunits and transporters (Fig. 3) after P2 HI, we investigated the capacity for an earlier form of anatomical plasticity in the somatotopic whisker representation. During a brief critical period from P1 to P3 in rodents, peripheral lesion of whisker follicles leads to a decrease of the cortical area represented by lesioned follicles with expansion of cortical area representing neighboring follicles (Van der Loos and Woolsey, 1973). To determine the effects of early $\mathrm{HI}$ on magnitude and timing of this critical period of plasticity, we removed the first four whisker follicles of the $\mathrm{C}$ row at P1, P2, P3, P5, or P7 in control rat pups or pups exposed to $\mathrm{HI}$ on the same day. Whisker lesion before P3 results in fusion and shrinkage of the deprived whisker barrels, with expansion of neighboring, undeprived rows (Fig. 7A, whisker lesion). Similar changes are observed in hemispheres exposed to hypoxia alone
(Fig. 7A, hypoxia lesion). However, in HI-exposed hemispheres, the C-row fuses but fails to contract (Fig. 7A, HI-lesion). The magnitude of whisker barrel plasticity can be quantified as a ratio of undeprived ( $\mathrm{D}$ row) area to deprived (C row) area: $\mathrm{D} / \mathrm{C}$ ratio. Mean $\pm-\mathrm{SD}$ D/C ratio in control animals is $1.2 \pm 0.1$ before $\mathrm{P} 3$ (Fig. $7 B$ ). After whisker lesion, the ratio increases to $1.8 \pm 0.3$ $(p<0.001)$. Hypoxia alone does not change the capacity for plasticity $(1.7 \pm 0.3, p<0.001)$, but $\mathrm{HI}$ attenuates the increase in $\mathrm{D} / \mathrm{C}$ ratio to no different than control $(1.4 \pm 0.2, p=0.06)$. When examining the individual D- and C-row areas at P3, failure of plasticity is accounted for by a lack of C-row contraction (Fig. 7C).

\section{Reduced activity in human preterm newborns with brain injury}

Finally, to explore whether similar changes of cortical activity occur after early brain injury in human preterm infants, we analyzed EEG recordings obtained in a subset $(n=36)$ of a larger cohort of premature newborns studied with early MRI to identify brain injury (Miller et al., 2005). Clinical characteristics are summarized in Table 1. Infants were born at a median GA of 28.4 weeks (range, 24.7-32.3 weeks) and weight of $1075 \mathrm{~g}$ (range, $540-1840 \mathrm{~g}$ ). MRI was performed at a median age of 30.7 weeks and EEG at a median age of 30 weeks. The groups did not differ with respect to age at MRI or EEG (all $p>0.1$ ) nor intervals between birth and EEG or MRI studies (all $p>0.1$ ). 

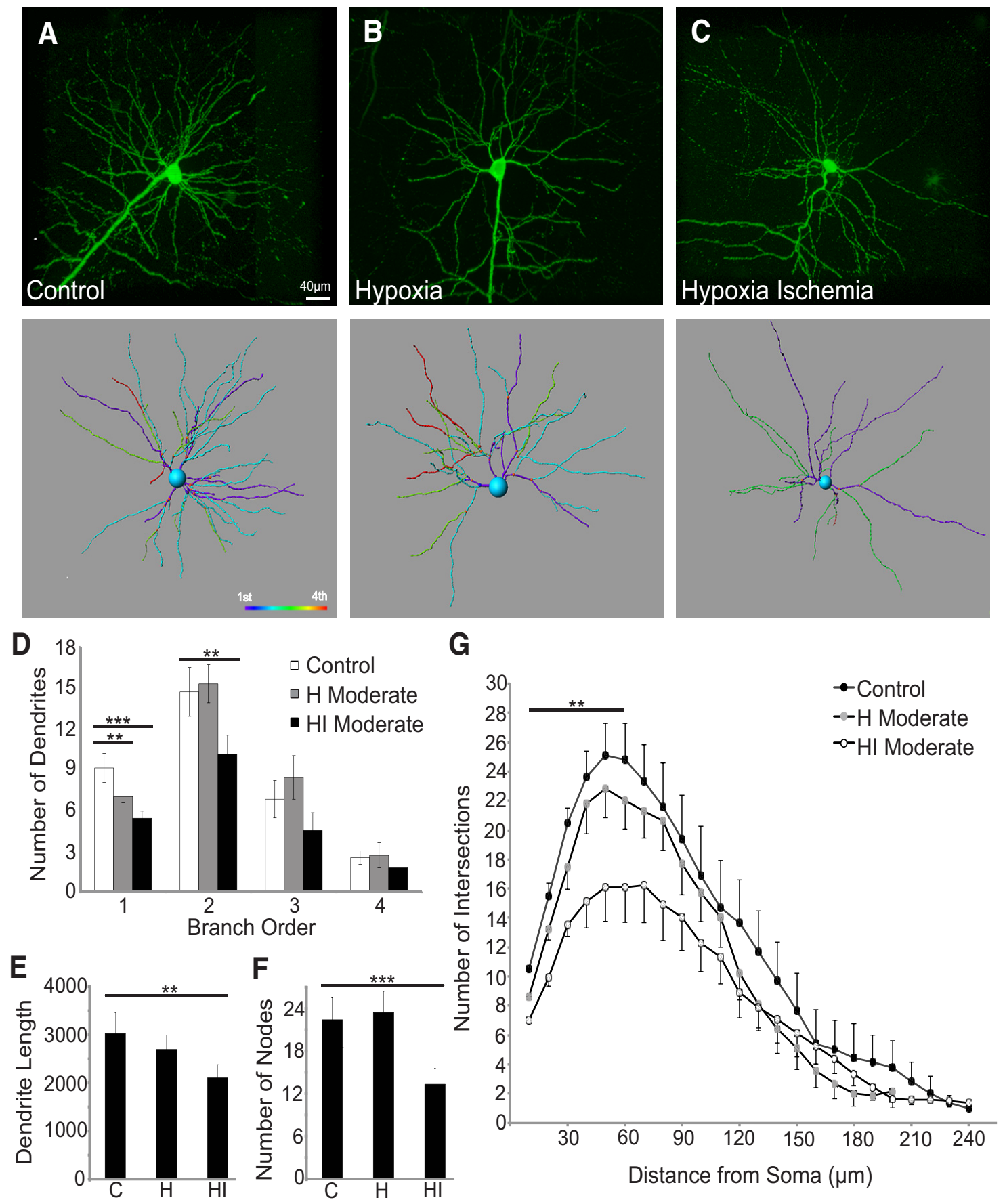

Figure 5. Dendrite development after neonatal HI. EGFP-labeled neurons imaged at $20 \times$ magnification (top row) with corresponding Imaris traced reconstructions color coded by dendrite level (bottom row). Each column represents examples of neurons from control $(\boldsymbol{C} ; \boldsymbol{A})$, hypoxia-only $(\boldsymbol{H} ; \boldsymbol{B})$, and $\mathrm{HI}(\boldsymbol{C})$ conditions. HI neurons resulted in simplified dendritic arborization as illustrated by decreased dendritic number $(\boldsymbol{D})$, total length $(\boldsymbol{E})$, and node number $(\boldsymbol{F})$. G, Sholl analysis of dendritic complexity. HI-treated neurons showed significantly decreased dendritic complexity from radius of $20-60 \mu \mathrm{m}$. Statistical significance determined by linear regression for repeated measures, generalized estimating equation accounting for repeated measures by animal. Scale bars, $50 \mu \mathrm{m}$. ${ }^{*} p \leq 0.05,{ }^{* *} p<0.01$. Ten neurons were analyzed per condition, sampled from six control animals and seven HI-exposed animals.

Twenty neonates had no brain injury $(n=18)$, minimal white matter injury (WMI; $n=1)$, or grade I IVH $(n=1)$, graded as described previously (Miller et al., 2005). These subjects comprised the control group. The injured group included a spectrum of severity of brain injury from moderate to severe. Eight newborns had either moderate $(n=2)$ or severe $(n=6)$ WMI. Five of these subjects with WMI also had grade II IVH and two had grade I IVH. Eight newborns had grade III IVH or periventricular hemorrhagic infarct according to the grading system of Papile
(Barkovich, 2000). Two of this group also had moderate periventricular WMI. Together, these infants $(n=16)$ comprised the brain-injured group. The two groups were not different with respect to birth weight, gender, or GA at birth (Table 1). As expected, the newborns with brain injury demonstrated overall higher illness severity as manifested by increased median days ventilated ( 9 vs $1 \mathrm{~d}, p<0.01$ ), infection ( 67 vs $45 \%, p<0.01$ ), and patent ductus arteriosus ( 73 vs $25 \%, p<0.01$ ). The incidence of necrotizing enterocollitis was low in both groups. Brain- 

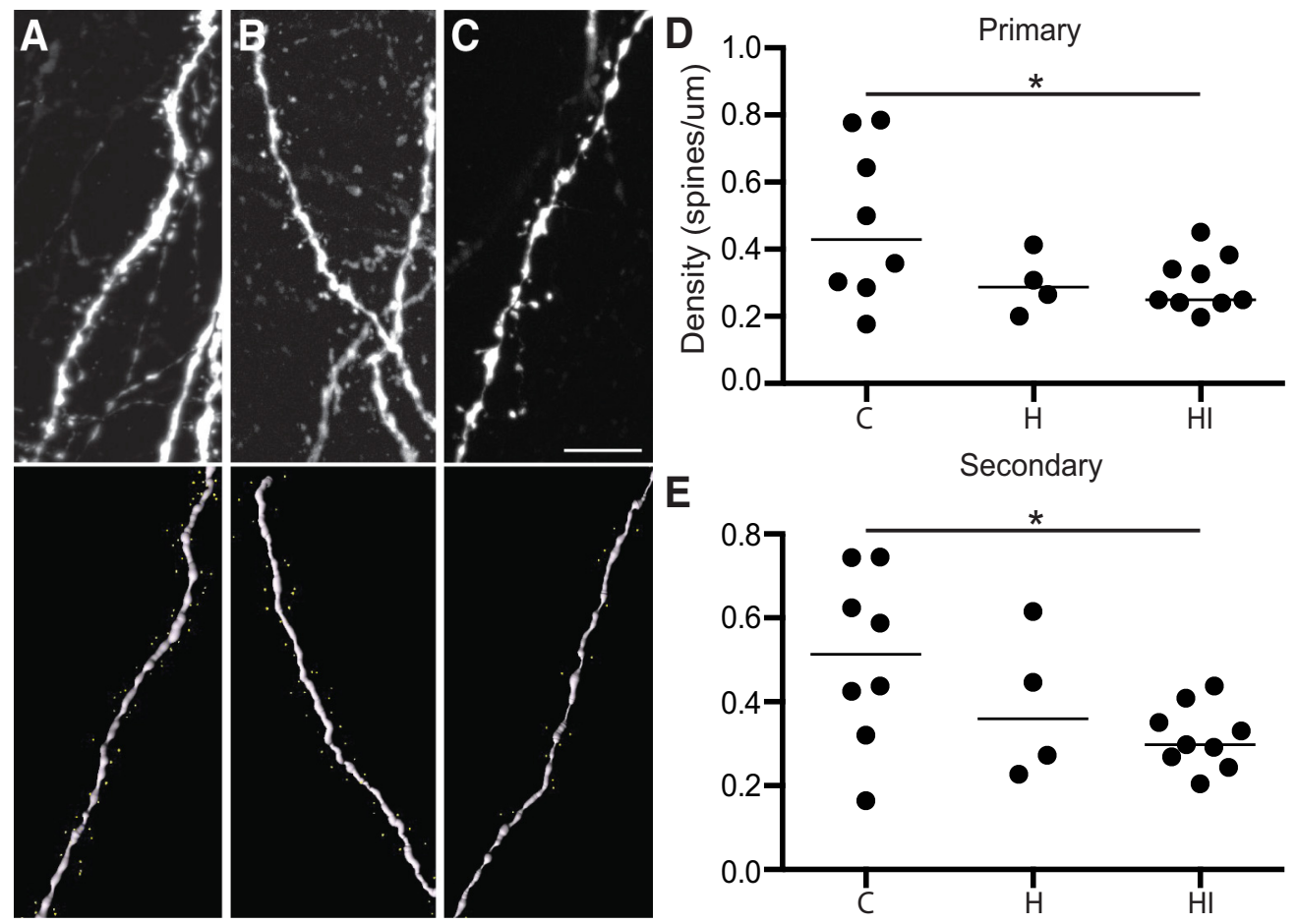

E

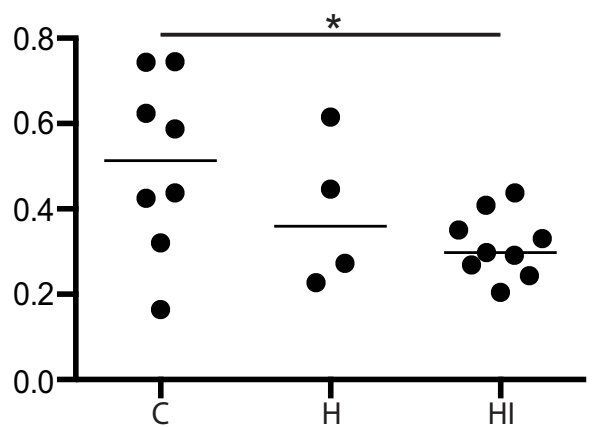

Figure 6. Spine density after neonatal HI. Segments of spiny dendrites labeled with EGFP reconstructed from high-resolution structured illumination microscopy z-stacks (top row) with corresponding Imaris traced reconstructions (bottom row). Each column represents segments from control $(C ; A)$, hypoxia-only $(H ; \boldsymbol{B})$, and $H I(C)$ conditions. Decreased spine density was observed in both primary $(\boldsymbol{D})$ and secondary $(\boldsymbol{E})$ dendrite segments. Statistical significance determined by linear regression for repeated measures, generalized estimating equation accounting for repeated measures by animal. ${ }^{*} p \leq 0.05$. Four animals were analyzed per condition with $n=12$ dendrite segments sampled in controls, $n=10$ segments in the hypoxia condition, and $n=18$ segments in the HI condition.

injured newborns were more likely to receive phenobarbital (33 vs $0 \%, p<0.01)$. Other medications that might suppress cortical activity were infrequent (e.g., narcotics, $n=3$; benzodiazepines, $n=1)$.

EEG recordings were reviewed by a clinical neurophysiologist (J.S.), blinded to injury category, for the presence of abnormal activity, developmental characteristics, and continuity. A single recording in a patient with periventricular hemorrhagic infarct and moderate WMI demonstrated severely depressed activity with burst suppression pattern after a seizure and was not analyzed further, leaving 15 subjects in the brain-injured group. Of the remaining 35 recordings, EEGs were developmentally normal in $29(83 \%)$. A higher percentage of EEGs in subjects with brain injury were abnormal ( 33 vs $5 \%, p=0.06$, Fisher's exact test). Abnormalities noted in six EEGs included asynchronous activity with bursts of polyspikes or fast activity. No electrographic seizures were observed in any of the remaining 35 recordings.

To determine the effect of brain injury on EEG background activity and patterns, the aEEG was derived from raw EEG recordings using the same MATLAB algorithm used in the animal studies. Similar to our findings in the rodent model and consistent with reports in the literature (Wikström et al., 2012), we found a significantly decreased aEEG lower margin amplitude in injured newborns compared with control newborns (Fig. 8A; mean $\pm \mathrm{SD}, 3.6 \pm 0.2$ vs $2.6 \pm 0.3 \mu \mathrm{V} ; p=0.003)$. We derived the complete population of IBIs for each EEG recording using a similar approach as in the animal model, with one modification: a continuous range of thresholds were applied to each case, and the threshold yielding the 80th percentile of maximum burst count was used. There was no difference in thresholds for control versus injured groups ( $p=0.91$; Table 1$)$. Population analysis of IBIs demonstrates a shift toward longer IBIs in injured neonates compared with the uninjured control neonates (Fig. $8 B ; p=0.02$ ).

Next, we sought to quantify oscillatory bursts in the alphabeta frequency band $(8-30 \mathrm{~Hz}$, spindle-like bursts). These bursts can occur in isolation or nested within slower delta waves, in which case they are referred to as delta brushes. Delta brushes are the dominant type of spontaneous cortical activity pattern that typically appear at $\sim 27$ weeks of gestation, peak at $\sim 32$ weeks, and disappear by term gestation (André et al., 2010). We found that these spindle-like bursts of alpha-beta oscillations were suppressed in the injured human brain compared with the control brain in our study cohort (median bursts per minute: injured vs control, 5.3 vs $8.1 ; p<0.01$, Student's $t$ test). When burst frequency was plotted as a function of GA, the developmental appearance and peak (30-32 weeks gestation) of this characteristic activity pattern can be appreciated in the control population (Fig. $8 C$ ). The burst rate was lower in the injured population at all ages and appeared to peak slightly later (Fig. 7C, 32-34 weeks). Conversely, median burst length is not different between the two populations ( 0.46 vs $0.46 s ; p=0.61)$. Spindle-like burst rate is significantly associated with both brain injury (coefficient, -2.9 ; $p=0.003$, univariate linear regression) and treatment with phenobarbital (coefficient, $-4.2 ; p=0.002$, univariate linear regression). When combined into a multivariable model correcting for GA at EEG, only brain injury remains significantly associated with lower burst rate (coefficient, $-2.1 ; p=0.04$, multivariable regression). Considering all medications that might suppress cortical activity (i.e., phenobarbital, narcotics, and benzodiazepines) only strengthens this result (coefficient, $-2.3 ; p=0.03$ ).

To explore the significance of both the type (WMI vs IVH) and severity of brain injury, we analyzed spindle-like burst count 
A
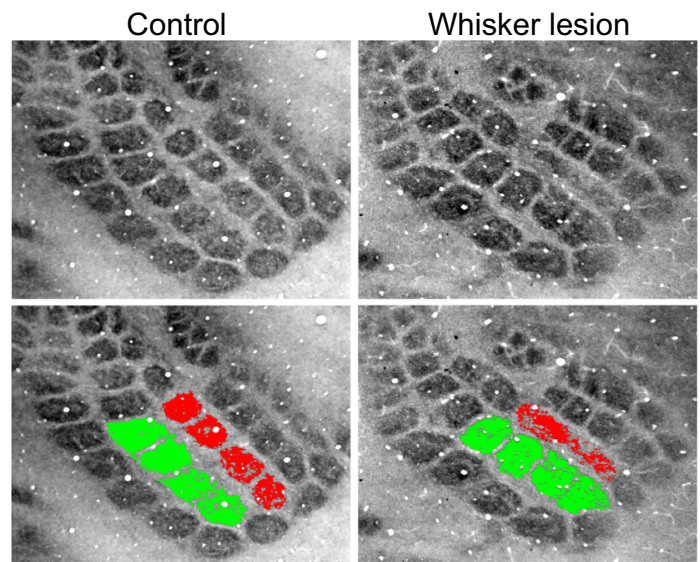

Hypoxia-lesion
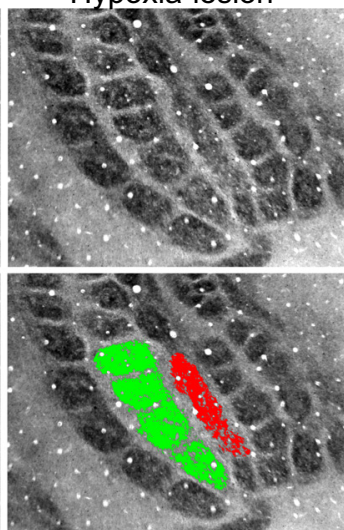

HI-lesion

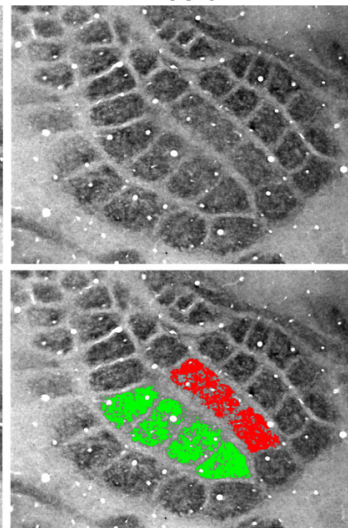

B

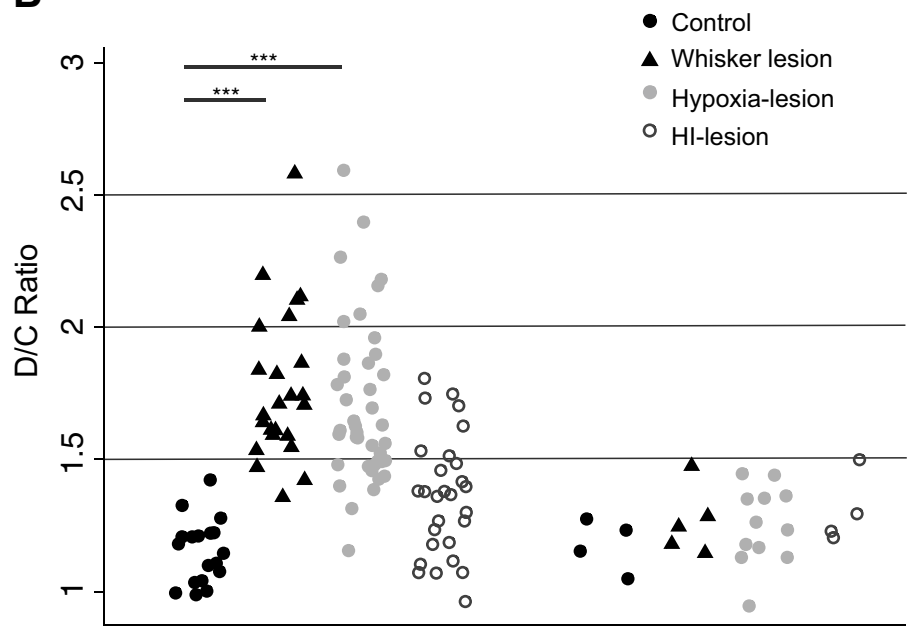

C 1.04
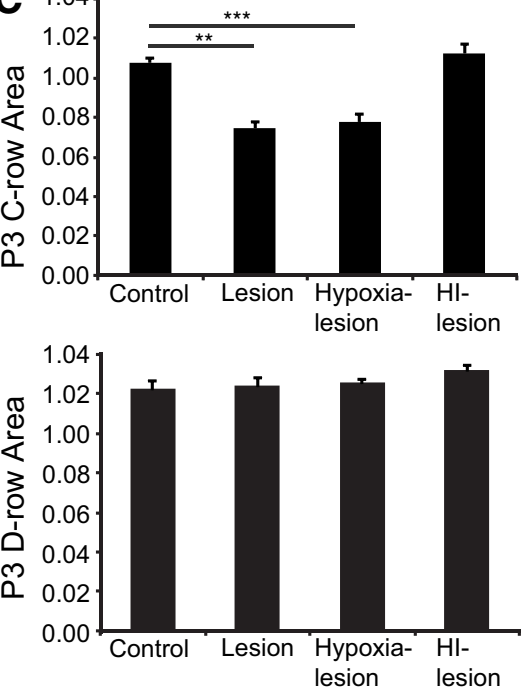

Figure 7. Whisker barrel plasticity. A, Cytochrome oxidase staining of tangential sections of somatosensory cortex demonstrates whisker barrels in control animals and after C-row whisker follicle lesions at P2 in control (no HI, no whisker lesion), whisker lesion (no HI, whisker lesion), hypoxia lesion (hypoxia, whisker lesion), or HI lesion (HI, whisker lesion) groups. D-row (green) and C-row (red) thresholded areas are measured in each group. $\boldsymbol{B}$, The D/C ratio is plotted for each group at selected age ranges. Whisker lesion during the critical period (P1-P3) increases the D/C ratio in control (whisker lesion) and hypoxia-exposed (hypoxia-lesion) hemispheres. However, $\mathrm{HI}$ at P1-P3 significantly attenuates whisker barrel plasticity during the critical period. Timing of the critical period is not changed as whisker lesion after P3 fails to change the $\mathrm{D} / \mathrm{C}$ ratio in all groups. $C$, Reduced plasticity at $\mathrm{P} 3$ is attributable to a failure of C-row contraction. D-row expansion is minimal at $\mathrm{P} 3$ in all groups. Significance testing was determined using one-way ANOVA with Bonferroni's correction. ${ }^{* *} p<0.01,{ }^{* * *} p<$ 0.001. For ages P1-P3, control $n=18$, control whisker lesion $n=24$, hypoxia whisker lesion $n=42$, HI lesion $n=33$. For ages P5 and P7 control $n=4$, control whisker lesion $n=$ 5, hypoxia whisker lesion $n=12$, HI lesion $n=4$.

Table 1. Patient and EEG characteristics

\begin{tabular}{lccc}
\hline Patient and EEG characteristics & Control & Injured & $p^{*}$ \\
\hline$n$ & 20 & 15 & \\
Sex (males), $n$ (\%) & $13(65)$ & $9(60)$ & 1.0 \\
Age at birth (weeks), median (IQR) & $28.4(27.6-29.3)$ & $27.7(25.3-30.1)$ & 0.37 \\
Age at EEG (weeks), median (IQR) & $30.0(28.9-31.2)$ & $30.3(29.0-32.0)$ & 0.75 \\
Age at MRI (weeks), median (IQR) & $30.2(29.7-32.0)$ & $31.7(30.7-32.4)$ & 0.10 \\
Birth weight (g), median (IQR) & $1087(974-1188)$ & $945(664-1450)$ & 0.29 \\
5 min APGAR, median (IQR) & $7(6.5-8)$ & $7(4-8)$ & 0.24 \\
Days ventilated, median (IQR) & $1(0-3.5)$ & $9(2-33)$ & $<0.01$ \\
Postnatal infection, $n$ (\%) & $9(45)$ & $10(67)$ & $<0.01$ \\
PDA, $n$ (\%) & $5(25)$ & $11(73)$ & $<0.01$ \\
NEC, $n$ (\%) & $1(5)$ & $1(7)$ & 1.0 \\
Phenobarbital, $n$ (\%) & $0(0)$ & $5(33)$ & $<0.01$ \\
Burst threshold (mV), median (IQR) & $4.5(4.0-6.2)$ & $5.2(3.6-7.4)$ & 0.91 \\
Burst frequency (n/min), median (IQR) & $8.1(6.5-9.1)$ & $5.3(2.2-7.4)$ & $<0.01$ \\
\hline
\end{tabular}

IQR, Interquartile range; $P D A$, patent ductus arteriosus; $N E C$, necrotizing enterocollitis.

*Kruskal-Wallis or Fisher's exact test. separately in subjects with either WMI or IVH (Fig. 8D). Spindlelike burst frequency is most depressed in subjects with significant IVH (grade III or periventricular hemorrhagic infarction), followed by significant WMI (moderate or severe; $p=0.01$, test for trend across ordered groups). Severity of brain injury also influences suppression of spindle-like burst frequency (Fig. $8 E$ ), with severe injuries (severe WMI or periventricular hemorrhagic infarction) suppressing spindle-like burst frequency more than moderate injuries (mild/moderate WMI or IVH grade II/III) ( $p=0.03$, test for trend across ordered groups).

\section{Discussion}

Here we show that early HI brain injury disrupts cortical activity in a neonatal rodent model, with similar findings in human preterm newborns with brain injury. Background activity is transiently diminished, and specific forms of patterned activity are reduced. In the rodent model, diminished activity is associated with delayed expression of activity-regulated proteins in layers IV and VI. Neuronal morphological development is delayed. Finally, 
whisker barrel plasticity is reduced, whereas barrel map formation is normal. Together, these results suggest a novel perspective on cortical circuit development after early brain injury that has relevance for adverse neurodevelopmental outcomes after extreme preterm birth in humans.

Previous studies in this model noted normal background activity and expression of activity-regulated proteins 2 weeks after injury (Failor et al., 2010). Consistent with these findings, aEEG baseline normalizes by P14. Although many aspects of visual system structure and function are preserved after neonatal HI (e.g., retinotopy, orientation selectivity), peak response to an optimal visual stimulus is markedly reduced, suggesting permanent cortical circuit abnormalities (Failor et al., 2010). Our results suggest a plausible mechanism for these findings. Spontaneous activity is necessary for normal maturation and development of cortical circuits, including upregulation of glutamatergic receptors and transporters and neuronal morphological development. Early spontaneous network oscillations amplify weak inputs to poorly responsive, developing circuits (Colonnese et al., 2010). From early ages, spontaneous and evoked gamma and spindle bursts activate and synchronize cortical columns (Yang et al., 2013). These data suggest a model whereby early brain injury impairs activity-dependent maturation of neuronal circuits during a sensitive period in which weak connections are consolidated and sharply tuned to relevant inputs. Although the basic circuits are intact after early brain injury, they are less responsive and less capable of multiple forms of plasticity. Neonatal HI is associated with premature death of subplate neurons (McQuillen et al., 2003), in addition to vulnerability and maturation arrest of oligodendrocyte progenitors (Back et al., 2002; Segovia et al., 2008). Subplate neurons play critical roles in early cortical development (for review, see Kanold and Luhmann, 2010). They receive the first thalamocortical input and in turn provide excitatory input to cortical layer IV in a transient circuit (Friauf and Shatz, 1991; Hanganu et al., 2002; Zhao et al., 2009). Subplate neurons are gap-junction coupled (DuPont et al., 2006) and receive both AMPA- and NMDA-mediated thalamic input, as well as local GABAergic and cholinergic activation (Hanganu et al., 2002). Subplate neurons participate in the generation of spontaneous cortical oscillations in vitro (DuPont et al., 2006), and targeted removal of subplate neurons in vivo mostly abolishes spindle bursts (Tolner et al., 2012). Subplate neurons are thought to promote maturation of both thalamus layer IV glutamatergic (Kanold et al., 2003) and GABA signaling (Kanold and Shatz, 2006). Consistent with these findings, the current results suggest a reduction in glutamatergic
A

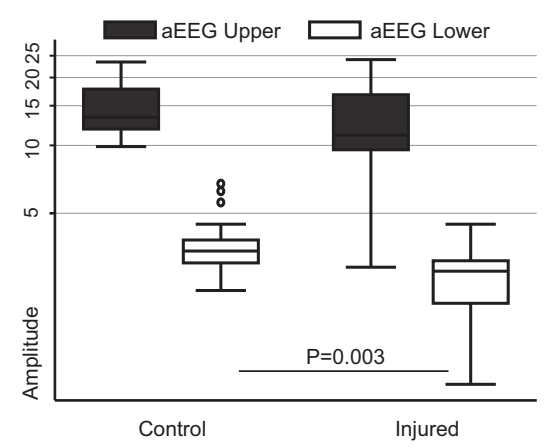

B

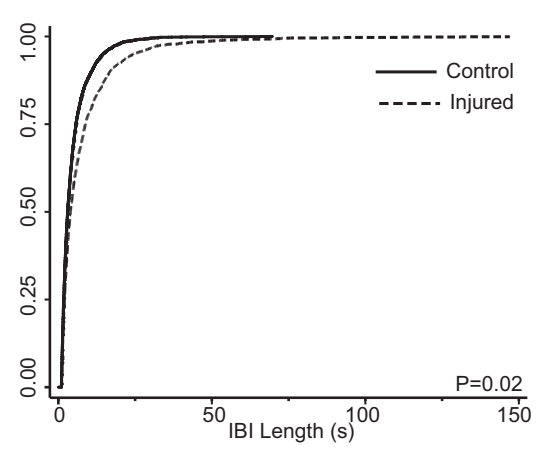

C

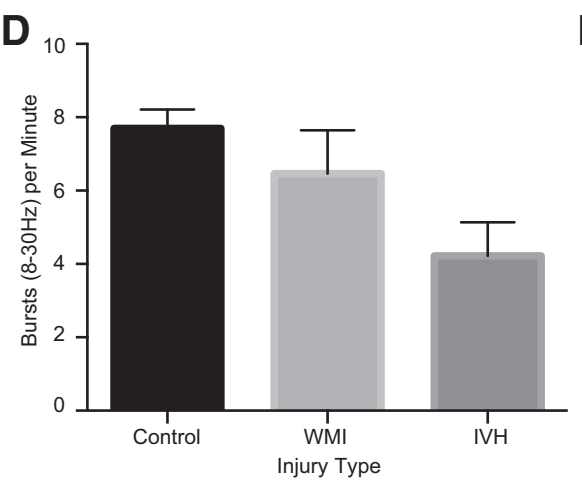

E

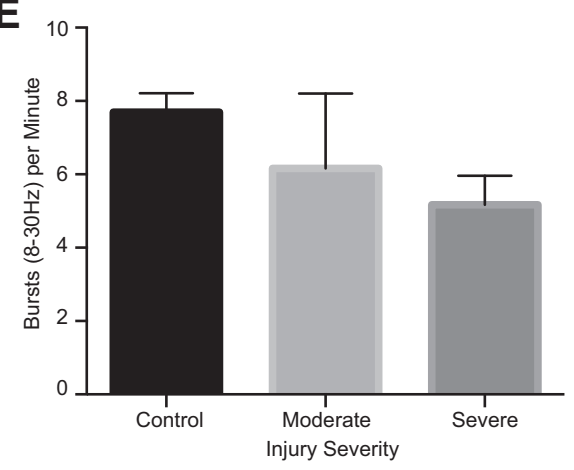

Figure 8. Cortical EEG activity in human preterm neonates. $A$, Summary of aEEG lower (white) and upper (black) margin amplitudes in control and brain-injured human preterm neonates. $\boldsymbol{B}$, Population distribution graphs of IBls of preterm neonates he GA showing that the brain-injured population (open circles) is clearly distinguishable from the control population (black minute in uninjured subjects or subjects with moderate (mild/moderate WMI or grade I//III IVH) or severe (severe WMI or periventricular hemorrhagic infarction) injury. Control (uninjured) $n=20$ and brain injured $n=15$ human preterm neonates.

synapse formation, as evidenced by reduced AMPA receptor puncta in layer IV. Unlike selective subplate removal with immunotoxin, neonatal HI may involve lower cortical layers depending on the severity of injury (McQuillen et al., 2003; Failor et al., 2010). After neonatal HI, we also see reduced glutamate receptor puncta in lower cortical layers, and this may represent a destructive effect of HI. However, early HI does not damage middle or upper cortical layers, suggesting that reduced glutamate receptor expression in layer IV may result from mechanisms similar to those described after immunotoxin subplate ablation. After subplate neuron immunoablation, evoked thalamocortical responses are weak, effectively uncoupling developing cortex from critical early excitatory input (Kanold et al., 2003).

Subplate neuron immunoablation prevents normal whisker barrel map formation (Tolner et al., 2012). After neonatal HI, we 
found normal barrel maps in all moderately injured animals. This is likely attributable to differences in the age and extent of subplate neuron ablation in the two models. Immunotoxin ablation was performed at P1, before whisker barrel maps have fully formed (Hensch, 2004). In contrast, HI is performed at P2 \pm $0.5 \mathrm{~d}$, after completion of map formation and near the end of the critical period for whisker barrel plasticity. Furthermore, immunotoxin ablation effectively removes all p75 neurotrophin receptor-expressing subplate neurons near the injection site, whereas after neonatal $\mathrm{HI}$, subplate neurons are reduced between 20 and $70 \%$ depending on injury severity. Finally, initiation of sensory map formation is exquisitely sensitive to timing of birth through mechanisms involving serotonin signaling (Toda et al., 2013). Thus, small differences in GA alone between the models $(\mathrm{P} 1$ vs $\mathrm{P} 2 \pm 0.5 \mathrm{~d})$ may explain the different effects on map formation.

Recent work has determined that subplate neurons also receive excitatory input from cortex, including layers V/VI (Viswanathan et al., 2012; Meng et al., 2014) and that subplate neurites are affected by peripheral sensory input in a similar manner to that of layer IV dendrites (Piñon et al., 2009). The present findings suggest that early $\mathrm{HI}$ leads to a reduction in cortical glutamatergic signaling based on EEG and glutamate receptor expression that involves at least layer IV, based on glutamate puncta and layer $\mathrm{V}$ excitatory pyramidal neurons based on spine counts. However, given the role of subplate neurons in maturation of inhibitory signaling (Kanold and Shatz, 2006), as well as the dynamic and bidirectional nature of this transient cortical circuit, further alterations in these developing cortical circuits are possible. This might include reduction in excitatory connections on inhibitory neurons and weakening of feedback inhibition. Both of which, along with strengthening of intracortical connections, might promote the observed recovery of background activity through homeostatic mechanisms. It is important to note that aEEG, particularly the lower aEEG margin, is most sensitive to background cortical activity. Thus, although background activity normalizes by P14, evoked responses remains reduced at least until the critical period (Failor et al., 2010). Additional studies with techniques such as cortical microstimulation (Viswanathan et al., 2012) are needed to fully understand changes in these microcircuits.

Neonatal HI impairs visual system ocular dominance plasticity during the critical period, which has onset 4 weeks after the initial injury at $\mathrm{P} 2$. In the present study, we note a reduced capacity but no change in timing of the critical period for early structural plasticity of the cortical whisker representation, which occurs at a much earlier age in the somatosensory cortex. In fact, differences in the timing and mechanisms of these cortical plasticity models are so extensive (Erzurumlu and Gaspar, 2012; Espinosa and Stryker, 2012) that comparisons must be made with caution. Loss of the astrocyte-specific glutamate transporters GLAST and GLT1 have been associated with reduced whisker barrel plasticity (Takasaki et al., 2008). Neonatal HI has been associated with lower expression of these transporters (Fukamachi et al., 2001), a finding we confirm. Furthermore, in GLT1 and GLAST knock-out mice, whisker lesion results in fusion of lesioned barrels but no contraction, and we find this identical phenotype after neonatal HI and whisker lesion. Finally, sensory deprivation by whisker trimming from birth results in decreased spine density and cortical neuronal dendritic complexity (Lee et al., 2009), a finding we also note after P2 HI. Simplified dendritic structure and decreased spine density were also noted in an ovine model of preterm brain injury (Dean et al., 2013) and linked to observations in human preterm infants of delayed microstructural development measured with diffusion tensor MRI (Vinall et al., 2013).

EEG in preterm newborns is associated with both brain injury and subsequent neurodevelopmental outcome (Wikström et al., 2012). Conventional EEG recording conditions include a low-cut filter that removes signals below $0.5 \mathrm{~Hz}$. Recent work using fullband EEG has demonstrated that the characteristic "discontinuity" and stereotypical activity patterns (e.g., delta waves) result from filtering slow-wave activity $(0.1-0.5 \mathrm{~Hz})$ (Vanhatalo and Kaila, 2006). Termed SATs by Vanhatalo and colleagues, SATs contain nested bursts of higher-frequency activity, including delta waves $(0.5-1 \mathrm{~Hz})$ and brushes $(8-30 \mathrm{~Hz})$, the human correlate of rodent spindles (Colonnese and Khazipov, 2010). An abrupt transition from bursting responses to mature visually evoked responses occurs just before eye opening (P14) in the rodent and at late GA (gestational week 36) in humans (Colonnese et al., 2010). Evoked responses become more temporally precise, whereas background activity becomes continuous with emergence of clear vigilance states. Loss of bursting responses is also associated with a maturation of inhibition. Consistent with this idea, we have reported delayed onset and reduced Parvalbumin expression in moderately injured animals that strongly correlated with impaired ocular dominance plasticity (Failor et al., 2010).

Our work has a number of important limitations. First, the spectrum of brain injuries in the injured premature newborns is more severe than described in contemporary cohorts (Hamrick et al., 2004; Woodward et al., 2006). This is attributable in part to selection bias from inclusion of subjects for whom EEGs were obtained for clinical indication. Human preterm brain injury is pleomorphic (WMI and IVH), and our animal model captures only a portion of this pathophysiology. To account for these issues, we analyzed spindle-like burst frequency in subgroups defined by injury type and severity. Although the sample is underpowered to detect group differences, we do find trends for increasing suppression according to injury type (IVH $>$ WMI). Second, EEG recording methods were chosen to duplicate those in current clinical use and thus include a low-cut filter that prevented us from directly visualizing and quantifying SATs and nested higher frequencies. A recent publication using an identical animal model and full-band intracortical recordings analyzed by time-frequency spectrogram has determined that early HI specifically diminishes the frequency of nested gamma spindle bursts but not isolated spindle bursts (Brockmann et al., 2013). Our method to quantify spindles and spindle-like bursts will detect both nested and isolated bursts. Nevertheless, both results are consistent with the finding that early brain injury reduces spindle bursts. Third, we did not assess glutamate receptor function beyond expression levels and pattern. A final limitation is that EEG recording conditions did not include sufficient information to precisely quantify sleep and wakefulness.

Many studies of early brain injury focus on cell death and potential repair through cell replacement. Our findings offer a broader view of the effects of injury with pervasive abnormalities of activity-dependent brain development after early brain injury that have a number of important clinical implications. First, these findings emphasize an expanded potential for using EEG as more than a clinical biomarker of brain injury. EEG can be seen as a real-time measurement of cortical circuit development, particularly in the transition from spontaneous to evoked activity. Second, our findings suggest that cortical activity may be a relevant target for therapeutic intervention. To realize this potential, fur- 
ther development of EEG recording and analysis will be necessary, including automated quantification of relevant parameters, such as delta waves (Mitchell et al., 2013), bursts/IBIs (Palmu et al., 2010), vigilance state, and SATs (Palmu et al., 2013). Increased monitoring of brain electrical activity may provide insight into beneficial effects of common clinical interventions such as caffeine, which is used to treat apnea of prematurity in humans (Schmidt et al., 2007). In human preterm newborns, caffeine treatment is associated with improved anatomical (Doyle et al., 2010) and functional (Schmidt et al., 2007) neurodevelopmental outcomes. The mechanism for the beneficial effects of caffeine is not known, although caffeine increases cerebral cortical activity measured by aEEG (Supcun et al., 2010). We suggest that restoration of early brain activity using easily adaptable clinical interventions such as caffeine treatment may offer a novel strategy to augment repair and recovery after early brain injury.

\section{References}

Ackman JB, Burbridge TJ, Crair MC (2012) Retinal waves coordinate patterned activity throughout the developing visual system. Nature 490:219225. CrossRef Medline

André M, Lamblin MD, d'Allest AM, Curzi-Dascalova L, MoussalliSalefranque F, Nguyen The Tich S, Vecchierini-Blineau MF, Wallois F, Walls-Esquivel E, Plouin P (2010) Electroencephalography in premature and full-term infants. Developmental features and glossary. Neurophysiol Clin Neurophysiol 40:59-124. CrossRef Medline

Back SA, Han BH, Luo NL, Chricton CA, Xanthoudakis S, Tam J, Arvin KL, Holtzman DM (2002) Selective vulnerability of late oligodendrocyte progenitors to hypoxia-ischemia. J Neurosci 22:455-463. Medline

Barkovich AJ (2000) Pediatric neuroimaging, Ed 3. Philadelphia: Lippincott Williams and Wilkins.

Blankenship AG, Feller MB (2010) Mechanisms underlying spontaneous patterned activity in developing neural circuits. Nat Rev Neurosci 11:18-29. CrossRef Medline

Brockmann MD, Kukovic M, Schönfeld M, Sedlacik J, Hanganu-Opatz IL (2013) Hypoxia-ischemia disrupts directed interactions within neonatal prefrontal-hippocampal networks. PLoS One 8:e83074. CrossRef Medline

Cang J, Rentería RC, Kaneko M, Liu X, Copenhagen DR, Stryker MP (2005) Development of precise maps in visual cortex requires patterned spontaneous activity in the retina. Neuron 48:797-809. CrossRef Medline

Chen Y, Ghosh A (2005) Regulation of dendritic development by neuronal activity. J Neurobiol 64:4-10. CrossRef Medline

Colonnese MT, Khazipov R (2010) "Slow activity transients" in infant rat visual cortex: a spreading synchronous oscillation patterned by retinal waves. J Neurosci 30:4325-4337. CrossRef Medline

Colonnese MT, Kaminska A, Minlebaev M, Milh M, Bloem B, Lescure S, Moriette G, Chiron C, Ben-Ari Y, Khazipov R (2010) A conserved switch in sensory processing prepares developing neocortex for vision. Neuron 67:480-498. CrossRef Medline

Conway B, Boyd JD, Stewart TH, Matsubara JA (2000) The projection from V1 to extrastriate area 21a: a second patchy efferent pathway that colocalizes with the CO blob columns in cat visual cortex. Cereb Cortex 10:149159. CrossRef Medline

Costeloe KL, Hennessy EM, Haider S, Stacey F, Marlow N, Draper ES (2012) Short term outcomes after extreme preterm birth in England: comparison of two birth cohorts in 1995 and 2006 (the EPICure studies). BMJ 345: e7976. CrossRef Medline

Dean JM, McClendon E, Hansen K, Azimi-Zonooz A, Chen K, Riddle A, Gong X, Sharifnia E, Hagen M, Ahmad T, Leigland LA, Hohimer AR, Kroenke CD, Back SA (2013) Prenatal cerebral ischemia disrupts MRIdefined cortical microstructure through disturbances in neuronal arborization. Sci Transl Med 5:168ra7. CrossRef Medline

Doyle LW, Cheong J, Hunt RW, Lee KJ, Thompson DK, Davis PG, Rees S, Anderson PJ, Inder TE (2010) Caffeine and brain development in very preterm infants. Ann Neurol 68:734-742. CrossRef Medline

Dupont E, Hanganu IL, Kilb W, Hirsch S, Luhmann HJ (2006) Rapid developmental switch in the mechanisms driving early cortical columnar networks. Nature 439:79-83. CrossRef Medline
Erzurumlu RS, Gaspar P (2012) Development and critical period plasticity of the barrel cortex. Eur J Neurosci 35:1540-1553. CrossRef Medline

Espinosa JS, Stryker MP (2012) Development and plasticity of the primary visual cortex. Neuron 75:230-249. CrossRef Medline

Failor S, Nguyen V, Darcy DP, Cang J, Wendland MF, Stryker MP, McQuillen PS (2010) Neonatal cerebral hypoxia-ischemia impairs plasticity in rat visual cortex. J Neurosci 30:81-92. CrossRef Medline

Feller MB, Scanziani M (2005) A precritical period for plasticity in visual cortex. Curr Opin Neurobiol 15:94-100. CrossRef Medline

Friauf E, Shatz CJ (1991) Changing patterns of synaptic input to subplate and cortical plate during development of visual cortex. J Neurophysiol 66:2059-2071. Medline

Fukamachi S, Furuta A, Ikeda T, Ikenoue T, Kaneoka T, Rothstein JD, Iwaki $\mathrm{T}$ (2001) Altered expressions of glutamate transporter subtypes in rat model of neonatal cerebral hypoxia-ischemia. Brain Res Dev Brain Res 132:131-139. CrossRef Medline

Glass HC, Bonifacio SL, Sullivan J, Rogers E, Ferriero DM, Goldstein R, Barkovich AJ (2009) Magnetic resonance imaging and ultrasound injury in preterm infants with seizures. J Child Neurol 24:1105-1111. CrossRef Medline

Goebel-Goody SM, Davies KD, Alvestad Linger RM, Freund RK, Browning MD (2009) Phospho-regulation of synaptic and extrasynaptic N-methyl-Daspartate receptors in adult hippocampal slices. Neuroscience 158:14461459. CrossRef Medline

Hamrick SE, Miller SP, Leonard C, Glidden DV, Goldstein R, Ramaswamy V, Piecuch R, Ferriero DM (2004) Trends in severe brain injury and neurodevelopmental outcome in premature newborn infants: the role of cystic periventricular leukomalacia. J Pediatr 145:593-599. CrossRef Medline

Hanganu IL, Kilb W, Luhmann HJ (2002) Functional synaptic projections onto subplate neurons in neonatal rat somatosensory cortex. J Neurosci 22:7165-7176. Medline

Hanganu-Opatz IL (2010) Between molecules and experience: role of early patterns of coordinated activity for the development of cortical maps and sensory abilities. Brain Res Rev 64:160-176. CrossRef Medline

Hayakawa M, Okumura A, Hayakawa F, Watanabe K, Ohshiro M, Kato Y, Takahashi R, Tauchi N (2001) Background electroencephalographic (EEG) activities of very preterm infants born at less than 27 weeks gestation: a study on the degree of continuity. Arch Dis Child Fetal Neonatal Ed 84:F163-F167. CrossRef Medline

Hensch TK (2004) Critical period regulation. Annu Rev Neurosci 27:549_ 579. CrossRef Medline

Hisaoka T, Nakamura Y, Senba E, Morikawa Y (2010) The forkhead transcription factors, Foxp1 and Foxp2, identify different subpopulations of projection neurons in the mouse cerebral cortex. Neuroscience 166:551563. CrossRef Medline

Jeanmonod D, Rice FL, Van der Loos H (1981) Mouse somatosensory cortex: alterations in the barrelfield following receptor injury at different early postnatal ages. Neuroscience 6:1503-1535. CrossRef Medline

Kanold PO, Luhmann HJ (2010) The subplate and early cortical circuits. Annu Rev Neurosci 33:23-48. CrossRef Medline

Kanold PO, Shatz CJ (2006) Subplate neurons regulate maturation of cortical inhibition and outcome of ocular dominance plasticity. Neuron 51: 627-638. CrossRef Medline

Kanold PO, Kara P, Reid RC, Shatz CJ (2003) Role of subplate neurons in functional maturation of visual cortical columns. Science 301:521-525. CrossRef Medline

Khazipov R, Sirota A, Leinekugel X, Holmes GL, Ben-Ari Y, Buzsáki G (2004) Early motor activity drives spindle bursts in the developing somatosensory cortex. Nature 432:758-761. CrossRef Medline

Kidokoro H, Inder T, Okumura A, Watanabe K (2012) What does cyclicity on amplitude-integrated EEG mean? J Perinatol 32:565-569. CrossRef Medline

Lee LJ, Chen WJ, Chuang YW, Wang YC (2009) Neonatal whisker trimming causes long-lasting changes in structure and function of the somatosensory system. Exp Neurol 219:524-532. CrossRef Medline

Maynard D, Prior PF, Scott DF (1969) Device for continuous monitoring of cerebral activity in resuscitated patients. Br Med J 4:545-546. CrossRef Medline

McQuillen PS, Sheldon RA, Shatz CJ, Ferriero DM (2003) Selective vulnerability of subplate neurons after early neonatal hypoxia-ischemia. J Neurosci 23:3308-3315. Medline 
Meng X, Kao JPY, Kanold PO (2014) Differential signaling to subplate neurons by spatially specific silent synapses in developing auditory cortex. J Neurosci 34:8855-8864. CrossRef Medline

Miller SP, Ferriero DM, Leonard C, Piecuch R, Glidden DV, Partridge JC, Perez M, Mukherjee P, Vigneron DB, Barkovich AJ (2005) Early brain injury in premature newborns detected with magnetic resonance imaging is associated with adverse early neurodevelopmental outcome. J Pediatr 147:609-616. CrossRef Medline

Mitchell TJ, Neil JJ, Zempel JM, Thio LL, Inder TE, Bretthorst GL (2013) Automating the analysis of EEG recordings from prematurely-born infants: a Bayesian approach. Clin Neurophysiol 124:452-461. CrossRef Medline

Moore T, Hennessy EM, Myles J, Johnson SJ, Draper ES, Costeloe KL, Marlow N (2012) Neurological and developmental outcome in extremely preterm children born in England in 1995 and 2006: the EPICure studies. BMJ 345:e7961. CrossRef Medline

Myers MM, Grieve PG, Izraelit A, Fifer WP, Isler JR, Darnall RA, Stark RI (2012) Developmental profiles of infant EEG: overlap with transient cortical circuits. Clin Neurophysiol 123:1502-1511. CrossRef Medline

Nakano H, Saito K, Suzuki K (1994) Chronic implantation technique for monopolar EEG monitoring of epileptic seizures in mice. Brain Res Bull 35:261-268. CrossRef Medline

Palmu K, Wikström S, Hippeläinen E, Boylan G, Hellström-Westas L, Vanhatalo S (2010) Detection of "EEG bursts" in the early preterm EEG: visual vs. automated detection. Clin Neurophysiol 121:1015-1022. CrossRef Medline

Palmu K, Kirjavainen T, Stjerna S, Salokivi T, Vanhatalo S (2013) Sleep wake cycling in early preterm infants: comparison of polysomnographic recordings with a novel EEG-based index. Clin Neurophysiol 124:18071814. CrossRef Medline

Piñon MC, Jethwa A, Jacobs E, Campagnoni A, Molnár Z (2009) Dynamic integration of subplate neurons into the cortical barrel field circuitry during postnatal development in the Golli-tau-eGFP (GTE) mouse. J Physiol 587:1903-1915. CrossRef Medline

Saneyoshi T, Fortin DA, Soderling TR (2010) Regulation of spine and synapse formation by activity-dependent intracellular signaling pathways. Curr Opin Neurobiol 20:108-115. CrossRef Medline

Sans N, Petralia RS, Wang YX, Blahos J 2nd, Hell JW, Wenthold RJ (2000) A developmental change in NMDA receptor-associated proteins at hippocampal synapses. J Neurosci 20:1260-1271. Medline

Schindelin J, Arganda-Carreras I, Frise E, Kaynig V, Longair M, Pietzsch T, Preibisch S, Rueden C, Saalfeld S, Schmid B, Tinevez JY, White DJ, Hartenstein V, Eliceiri K, Tomancak P, Cardona A (2012) Fiji: an opensource platform for biological-image analysis. Nat Methods 9:676-682. CrossRef Medline

Schmidt B, Roberts RS, Davis P, Doyle LW, Barrington KJ, Ohlsson A, Solimano A, Tin W (2007) Long-term effects of caffeine therapy for apnea of prematurity. N Engl J Med 357:1893-1902. CrossRef Medline

Seelke AMH, Blumberg MS (2008) The microstructure of active and quiet sleep as cortical delta activity emerges in infant rats. Sleep 31:691-699. Medline

Segovia KN, McClure M, Moravec M, Luo NL, Wan Y, Gong X, Riddle A, Craig A, Struve J, Sherman LS, Back SA (2008) Arrested oligodendrocyte lineage maturation in chronic perinatal white matter injury. Ann Neurol 63:520-530. CrossRef Medline

Spitzer NC (2006) Electrical activity in early neuronal development. Nature 444:707-712. CrossRef Medline

Supcun S, Kutz P, Pielemeier W, Roll C (2010) Caffeine increases cerebral cortical activity in preterm infants. J Pediatr 156:490-491. CrossRef Medline
Takasaki C, Okada R, Mitani A, Fukaya M, Yamasaki M, Fujihara Y, Shirakawa T, Tanaka K, Watanabe M (2008) Glutamate transporters regulate lesion-induced plasticity in the developing somatosensory cortex. J Neurosci 28:4995-5006. CrossRef Medline

Toda T, Homma D, Tokuoka H, Hayakawa I, Sugimoto Y, Ichinose H, Kawasaki $H$ (2013) Birth regulates the initiation of sensory map formation through serotonin signaling. Dev Cell 27:32-46. CrossRef Medline

Toet MC, Hellström-Westas L, Groenendaal F, Eken P, de Vries LS (1999) Amplitude integrated EEG 3 and 6 hours after birth in full term neonates with hypoxic-ischaemic encephalopathy. Arch Dis Child Fetal Neonatal Ed 81:F19-F23. CrossRef Medline

Tolner EA, Sheikh A, Yukin AY, Kaila K, Kanold PO (2012) Subplate neurons promote spindle bursts and thalamocortical patterning in the neonatal rat somatosensory cortex. J Neurosci 32:692-702. CrossRef Medline

Towfighi J, Mauger D, Vannucci RC, Vannucci SJ (1997) Influence of age on the cerebral lesions in an immature rat model of cerebral hypoxiaischemia: a light microscopic study. Brain Res Dev Brain Res 100:149_ 160. CrossRef Medline

Tucker AM, Aquilina K, Chakkarapani E, Hobbs CE, Thoresen M (2009) Development of amplitude-integrated electroencephalography and interburst interval in the rat. Pediatr Res 65:62-66. CrossRef Medline

Van der Loos H, Woolsey TA (1973) Somatosensory cortex: structural alterations following early injury to sense organs. Science 179:395-398. CrossRef Medline

Vanhatalo S, Kaila K (2006) Development of neonatal EEG activity: from phenomenology to physiology. Semin Fetal Neonatal Med 11:471-478. CrossRef Medline

Vinall J, Grunau RE, Brant R, Chau V, Poskitt KJ, Synnes AR, Miller SP (2013) Slower postnatal growth is associated with delayed cerebral cortical maturation in preterm newborns. Sci Transl Med 5:168ra8. CrossRef Medline

Viswanathan S, Bandyopadhyay S, Kao JP, Kanold PO (2012) Changing microcircuits in the subplate of the developing cortex. J Neurosci 32: 1589-1601. CrossRef Medline

West AE, Greenberg ME (2011) Neuronal activity-regulated gene transcription in synapse development and cognitive function. Cold Spring Harb Perspect Biol 3(6). CrossRef

Wikström S, Pupp IH, Rosén I, Norman E, Fellman V, Ley D, HellströmWestas L (2012) Early single-channel aEEG/EEG predicts outcome in very preterm infants: Early aEEG/EEG predicts outcome in preterms. Acta Paediatr 101:719-726. CrossRef Medline

Wilson-Costello D, Friedman H, Minich N, Fanaroff AA, Hack M (2005) Improved survival rates with increased neurodevelopmental disability for extremely low birth weight infants in the 1990s. Pediatrics 115:997-1003. CrossRef Medline

Woodward LJ, Anderson PJ, Austin NC, Howard K, Inder TE (2006) Neonatal MRI to predict neurodevelopmental outcomes in preterm infants. N Engl J Med 355:685-694. CrossRef Medline

Xu HP, Furman M, Mineur YS, Chen H, King SL, Zenisek D, Zhou ZJ, Butts DA, Tian N, Picciotto MR, Crair MC (2011) An instructive role for patterned spontaneous retinal activity in mouse visual map development. Neuron 70:1115-1127. CrossRef Medline

Yang JW, An S, Sun JJ, Reyes-Puerta V, Kindler J, Berger T, Kilb W, Luhmann HJ (2013) Thalamic network oscillations synchronize ontogenetic columns in the newborn rat barrel cortex. Cereb Cortex 23:1299-1316. CrossRef Medline

Zhao C, Kao JP, Kanold PO (2009) Functional excitatory microcircuits in neonatal cortex connect thalamus and layer 4. J Neurosci 29:1547915488. CrossRef Medline 